\title{
What Happens When a Woman Wins a Close Election? Evidence from Brazil*
}

\author{
Fernanda Brollo \\ University of Alicante
}

\author{
Ugo Troiano
}

Harvard University

\author{
First Version, April 2011 \\ This Version, December 2012
}

\begin{abstract}
This paper studies the effect of women's leadership on policy outcomes in close races utilizing a rich dataset on Brazilian municipalities. We provide evidence that cities with female mayors have better health outcomes (prenatal visits and percentage of premature births), are awarded more federal discretionary transfers, and are less likely to have administrative irregularities in public procurement practices. Despite these results, male mayors are 20 percentage points more likely to be re-elected than female mayors. We discuss several interpretations of our results, including the role of political patronage and re-election incentives. We find that men are more likely to hire temporary public employees during the electoral year compared to their female counterparts. This effect is driven by incumbents who are eligible for re-election.
\end{abstract}

\footnotetext{
*Fernanda Brollo, fernanda.brollo@ua.es, Ugo Troiano, troiano@fas.harvard.edu .We thank Larry Katz for initial encouragement and for comments. We wish to thank Philippe Aghion, Alberto Alesina, Robert Barro, Lorenzo Casaburi, Raj Chetty, Decio Coviello, David Cutler, Jeff Frieden, Ed Glaeser, Michael Kremer, David Laibson, Tommaso Nannicini, Rohini Pande, Nicola Persico, Renata Rizzi, Francesco Sobbrio and seminar audiences at the Harvard Development, Labor and Macro Lunch, LACEA, Petralia Workshop, UCL and University of Alicante for their comments. Fernanda Brollo thanks the Spanish Ministry of Education and Federal Funds for financial support under project SEJ 2007-62656. This work was partially conducted while Ugo Troiano was a Giorgio Ruffolo Fellow in the Sustainability Science Program and an economics graduate student at Harvard University. Support from Italy's Ministry for Environment, Land and Sea and the Harvard Economics Department is gratefully acknowledged. We thank Maria Sole Pagliari for research assistance. All errors are our own.
} 


\section{Introduction}

In recent years the idea that women are a positive force in political systems has spread. ${ }^{1}$ According to the experimental literature the choices women make are more socially oriented than men's. ${ }^{2}$ In Brazil, the country targeted in this research, during the first three months of the mandate of the current president, Dilma Rousseff, four ministers were forced to resign because of corruption scandals. Dilma's government has became famous for the faxina (cleaning) of corruption she has promoted, which has jeopardized congressional support, particularly because most revelations fell on the heads of parties within the government's coalition.

In this paper, we study what happens when a woman takes office after facing tough electoral competition with a man. Political agency has its own idiosyncrasies, and it is unclear whether the gender differences found in the lab should persist in this setting. ${ }^{3}$

We use Brazilian data and exploit a Regression Discontinuity (RD) design in close electoral races to control for unobservables city-specific confounding factors. We provide new evidence on the impact of a politicians gender in close elections by comparing places where a male candidate barely won with places where a female candidate barely lost. The research questions and findings of this paper can be summarized as follows.

First, we study whether the allocation of infrastructure transfers in Brazil is influenced by the gender of the politician after a contested election between two candidates of different sex. The effort of the mayor is one of the important determinants for attracting those transfers because the municipal administration presents a detailed project proposal, including its expected timeline, and the quality of this proposal determines the allocation of those transfers. We find that a man who wins a close election against a woman attracts around $50 \%$

\footnotetext{
${ }^{1}$ For example, Swamy et al. (2001) use micro data to show that women are less involved in bribery. Dollar et al. (2001) show that corruption is less severe in the countries where women constitute a majority of parliamentary seats, senior positions in the government bureaucracy, and the labor force. Anzia and Berry (2011), analyzing changes within districts over time, find that congresswomen are associated with attracting roughly $9 \%$ more spending from federal discretionary programs than congressmen and sponsor and cosponsor significantly more bills than their male colleagues.

${ }^{2}$ See Eckel and Grossman, 2008. Nowell and Tinkler (1994) report significantly higher contributions by women than by men in public goods game. Andreoni and Vesterlund (2001) conduct a modified dictator experiment and find that women gave away more tokens than men.

${ }^{3} \mathrm{~A}$ family of theoretical models that would be consistent in finding a gender differences in policies would be one in which politicians have different bliss points (Alesina, 1988), and this difference is correlated with gender. This can be supported -among others- by the findings in Edlund and Pande (2001).
} 
less infrastructure transfers than their female counterpart. We are able to distinguish between discretionary and non-discretionary transfers, and we find that the effect is concentrated only on the former. These effects can be interpreted in two different ways. The first interpretation is that female mayors put more effort in writing a successful application. The effort can be due to intrinsic characteristics or to incentives reasons, such as re-election. A second interpretation is that the President, who decides which applications are accepted, could favor politicians with certain qualities. Although we cannot disentangle between those two channels, we will provide evidence that the gender difference in attracting transfers is not affected by whether the term limit is binding for the incumbent. This evidence is inconsistent with the possibility that female mayors put more effort into attracting transfers for re-election concerns.

Second, we study whether the gender of the policymaker is linked to prenatal care outcomes. The results indicate that, in close races, municipalities with a male mayor present a higher percentage of women without any pre-natal visits (60\% of the sample mean) and a lower percentage of non-premature births (1.3\% of the sample mean). Consistently with Fujiwara (2010), we find that the effect of policies on health outcomes are concentrated for babies delivered by less educated mothers.

Third, we investigate whether the gender of the politician who wins a close race affects which types of administrative irregularities are pointed out in the audit reports for municipal administrations in randomly selected municipalities. We collect data for all municipalities with a mixed gender election where randomly allocated audit reports were available. By using this subset of municipalities we provide evidence that male mayors have a higher probability of engaging in corruption episodes and in illegal procurement practices. The size of the effect ranges from $33 \%$ to $38 \%$ and from $18 \%$ to $33 \%$, respectively, although the sample size is limited and it should be taken with caution, although it is reassuring that it comes from a random draw of municipalities.

Subsequently, we ask whether the probability of re-election or the decision to re-run after a close mixed gender election is affected by the gender of the incumbent. We find that female candidates elected after a contested mixed election have a 20 percentage points (50 percent of the sample mean) lower probability of being reelected compared to their male counterparts, even if they have the same probability of deciding to run for re-election after the first term. 
These findings can be interpreted in several ways. To shed light on the different potential explanations for our results, we first look at public employment outcomes, and we then look at whether term limits are driving our findings. We find that male mayors hire more temporary employees during the electoral year than female mayors, on average. However, we do not find any significant difference for non-temporary public employees. These results suggest that male mayors might be promoting more political patronage than their female counterpart. This is a plausible explanation for the "incumbency advantage" of male mayors in close races even if women seem to be better administrators. Although political patronage is present in Brazil and has received considerable attention among Brazilian scholars, there could be other alternative explanations for the electoral results. ${ }^{4}$ For instance, men could be better than women on some unobservable policies that the econometrician cannot observe, or voters might discriminate against women incumbents. ${ }^{5}$ However, it is reassuring that a rich set of observable variables, that include the gender wage gap, is balanced in gender mixed close races. See the description of the validity tests on Section 5.1.

We shed light on whether re-election incentives differentially affect mayors of different genders, by using municipal term limits. To the best of our knowledge, this is one of the first attempts in the literature to try to understand whether the response to electoral incentives is gender differentiated. We find that the gender differences on the number of temporary public employees are driven by mayors in their first term (who are allowed to run for re-election). The differences in the number of pre-natal visits are driven by lame duck mayors (higher fraction of women with no pre-natal visits), while the difference in the allocation of transfers is constant across the two terms. These results suggest that re-election incentives seem to be harsher on men. One of the explanations that can potentially rationalize this result is that the extent to which politicians seek the support of special-interest groups could be gender differentiated (Olson, 1965; Barro, 1973; Persson Tabellini, 2000). While female mayors seem to put more effort into obtaining better prenatal care outcomes for their constituency, our

\footnotetext{
${ }^{4}$ See Engerman and Sokoloff, 2002; Weyland, 1996; Mainwaring, 2002; Ames, 1995 for a discussion on political patronage in Brazil.

${ }^{5}$ Anecdotal evidence suggests that voters in Brazil have attitudes that are averse to women. For example, $48 \%$ of the Brazilians interviewed by the World Values Survey agree with the following statement "Men make better political leaders than women do", while the corresponding number for USA is $27 \%$. Additionally, $37 \%$ of the Brazilians in the same survey agree with the following statement "Men should have more right to a job than women" while the corresponding number for USA is 19\%.See for example Goldin and Rouse (2000) and Pino (2011) for evidence on gender discrimination.
} 
results suggest that male mayors target special-interest groups of voters by increasing the size of temporary public employees of the municipality.

Our results are subject to some caveats. First, the effect we are identifying does not necessarily reflect what would happen by introducing rigid quotas, but identifies the effect off those women who are closely competing against a man in the absence of institutional constraints. ${ }^{6}$ We see this as an advantage and not as a limitation because it allows us to analyze gender difference in a context where a woman faces competition from a man, and it allows us to identify a local average treatment effect with potentially different policy implications than those resulting from a research design based on randomly assigned quota. We discuss these issues further while commenting on our results and in the conclusion. Second, we are estimating an effect that is local with respect to close mixed gender elections. As usual in RDD, the gain in internal validity might come at the price of lower external validity, and the effect that we estimate might not apply to different situation, such as the elections where every candidate is the same gender.

The paper proceeds as follows. Section 2 discuss the literature. Section 3 describes the Brazilian institutional framework. Section 4 lays out our identification and estimation strategy. Section 5 discusses the empirical results and validity tests. In Section 6 the conclusion.

\section{Literature Review}

This paper contributes to two strands of literature. First, we contribute to the literature of women's empowerment and economic development. This literature has been recently reviewed by Doepke, Tertilt and Voena (2011) and Duflo (2011). Second, we add to the literature on gender and labor market outcomes (i.e., in leadership position). This literature has been recently reviewed by Bertrand (2011).

It is beyond the scope of this paper to review all the papers in these two strands literature. However, in this section we will discuss some of the papers that are particularly related to ours. Recent evidence showed that there is a clear difference in career path between women and men executives or political leaders. Bertrand, Goldin and Katz (2010) showed that although male and female MBAs have nearly identical earnings at the outset of their

\footnotetext{
${ }^{6}$ Chattopadhyay and Duflo (2004), Fréchette and Morelli (2008) and De Paola, Scoppa and Lombardo (2010) analyze in detail the effect of introducing gender quotas in different settings.
} 
careers, their earnings soon diverge, with the male earnings advantage reaching almost 60 log points a decade after MBA completion. Gagliarducci and Paserman (2012) show that in Italian municipalities headed by female mayors, the probability of early termination of the legislature is higher. Ferreira and Gyourko (2010) show that while female US mayors do not implement different observable policies, they do appear to have higher unobserved political skills, as they have a 6-7 percentage point higher incumbency advantage than a comparable male. ${ }^{7}$ Additionally, a rapidly growing literature starting with Chattopadhyay and Duflo (2004) focused on studying the effect of reservation policy for women in India; they provide credible evidence according to which political leaders invest more in infrastructure that is directly relevant to the needs of their own genders.

We add to this literature by analyzing a rich dataset on Brazilian municipalities and providing new evidence on the role of gender in politics. First of all, the Brazilian institutional setting allows us to provide evidence that is directly linked to the effort of the mayor in representing her own constituency, such as an administrative measure of corruption, the ability to attract discretionary transfers or political patronage. Secondly, by using the fact that Brazilian mayors are subject to a two-term limit, we move a first step in understanding whether re-election incentives matter for the gender difference in political performance.

\section{Institutions and Data}

\subsection{The Brazilian federal system, the allocation of infrastructure transfers and electoral data}

The Brazilian presidential federal system takes place in a context of a multi-party system. ${ }^{8}$ The political and administrative organization of Brazil comprises the federal government, the states, the federal district and the municipalities. The municipalities are minor federative units. Each municipality has an autonomous local government, comprising a mayor, directly elected by the people to a four-year mandate, and a legislative body, also directly elected by voters. Mayors of municipalities above 200,000 voters are directly elected by a majority runoff rule, while mayors of municipalities below 200,000 are directly elected with plurality

\footnotetext{
${ }^{7}$ See also Lee, Moretti, and Butler (2004), Lee (2008), Pettersson-Lidbom (2008), Vogl (2012) or Brollo and Nannicini (2012) for other examples of RDD in close elections.

${ }^{8}$ This subsection relies heavily upon Brollo and Nannicini (2012).
} 
rule. ${ }^{9}$ Before 1998 Brazilian mayors could not run for re-election. After 1998, mayors were allowed to run for a second term. The elections of the President, governors, and members of Congress all take place at the same time every four years, while municipal elections are staggered by two years and also take place every four years. In our study we are considering two municipal administration mandates: 2001-2004 and 2005-2008. Electoral data come from

\section{Tribunal Superior Eleitoral.}

Since the constitution was ratified in Brazil in 1988, municipal administrators have become increasingly responsible for delivering a relevant share public services related to education, health, and infrastructure projects. Mayors have the veto power over the budget.

The resources of Brazilian municipalities come from (a) local revenues, such as fines, exemptions, service taxes (ISS), and residential property taxes (IPTU); (b) transfers from federal, state and municipal governments. The most important source of municipal revenues is represented by federal transfers, which on average amount to $65 \%$ of the municipal budget. There are two different types of transfers: (1) constitutional automatic transfers (i.e. Fundo de Participação do Municipio - FPM and "Transferências Legais") ; and (2) discretionary transfers - CONVENIO agreements. ${ }^{10}$ Most of them are subject to the execution of federal budgetary amendments. Most of them (82\%) are earmarked for infrastructure projects. Apart from some big cities, such as Brazilian state capitals, municipalities are strongly dependent on these transfers as their sources of revenue (tax revenue represents only $5.5 \%$ of the municipal total revenues, on average). ${ }^{11}$

This study focuses on discretionary transfers devoted to infrastructure projects, which amount to about $15 \%$ of total municipal expenditure in infrastructures. These transfers are related to budget items that involve the construction of buildings and bridges, the paving of

\footnotetext{
${ }^{9}$ See Fujiwara (2011) for an analysis of the effects of the electoral rule in Brazilian municipalities.

${ }^{10}$ The allocation mechanism of FPM tranfers (which corresponds to $75 \%$ of federal transfers) depends on the population size and the state in which the municipality is located. From this total amount of federal transfers received by each municipality, there are also fixed coefficients that establish the amount of funds. $70 \%$ of FPM transfers are unrestricted and $30 \%$ to be converted into education and health expenditures: $15 \%$ in education and 15\% in health. Another type of constitutional transfers are "Transferências Legais") . These transfers can be targeted to different areas (education, health, social assistance, etc). These transfers are based on income per-capita or number of children enrolled in school. In this way, mayors cannot exert additional/less effort to increase/decrease the amount of FPM transfers and "Transferências Legais") nor can the central government cut these transfers.

${ }^{11}$ We calculate these percentages with data from FINBRA. See the subsection below where we give detailed information on our data.
} 
roads, the improvement of water and sewer systems, the purchase of ambulances, and so on. We focus on this type of federal transfers because the bulk of the other revenues are largely non-discretionary and hard to manipulate. ${ }^{12}$

In order to understand the determinants of discretionary transfers we should analyze the Brazilian budget process. The budget law is not mandatory in Brazil, the President has a major role in deciding the exact allocation of the discretionary transfers and can thus use them to make deputies follow the guidelines of the government coalition. Municipal governments must exert effort to receive these transfers, because a budgetary amendment can be executed only when an agreement between the municipality and the central government is signed.

There are two different ways of applying for discretionary transfers (CONVÊNIO agreements): (1) Municipalities directly send their project to the ministry of interest. Transfers can be sent directly to municipalities. In this cases, expenditures are typically proposed in the executive's initial budget bill. (2) Via budgetary amendments. In this case, projects are subject also by legislators approval and after payment by President which has veto power. Therefore, voters in a given municipality will receive discretionary infrastructure transfers depending on three factors: (i) The effort of their municipal administration in applying for transfers; (ii) the interest of a federal deputy; and (iii) the interest of the President in executing the budget amendment (i.e., send the money exactly to that municipality).

Data on infrastructure transfers is obtained on the Brazilian National Treasure Website (Tesouro Nacional) - FINBRA dataset, which provides information from municipal and state annual balance sheets. ${ }^{13}$ This is self-reported data from municipalities. The National Treasure, which organizes it. ${ }^{14}$

\footnotetext{
${ }^{12}$ As a falsification test, we also performed RDD estimations on constitutional automatic transfers (FPM), detecting no effect of gender on their allocation (results available upon request).

${ }^{13}$ The variable used in the first part of the analysis is the log of total amount of the per-capita infrastructure transfers. We choose the log specification given the skewness of the transfers received by the municipalities. Municipalities that do not receive infrastructure transfers, are not dropped when we run the log specification. For the $\log$ transformation we considered a reported amount of $\mathrm{R} \$ 1,00$, then, the log amount is zero. All budget variables are in real values, base year 2006 (IPCA - FGV deflator). Alternatively, we estimate a Poisson regression considering as an outcome the transfers per capita, and our results are unchanged. Results are available upon request.

${ }^{14}$ Only since 2002 has it been possible to distinguish discretionary from constitutional transfers that finance infrastructure projects. For consistency, the period of analysis (2001-2008) considers the overall amount of federal infrastructure transfers (Transferências de Capital). On average, $78 \%$ of the total amount of infrastructure transfers is discretionary (CONVÊNIO). Note that after year 2002 FINBRA brings information on discretionary (CONVÊEIO) and constitutional infrastructure transfers. The percentage of discretionary
} 


\subsection{The health care system in Brazil}

The health sector in Brazil has been reformed since new National Constitution of 1988. Particularly with the creation of the Unified Health System (SUS) in 1990. One of the most important characteristics of SUS is the decentralization. That is, the SUS has transferred responsibilities and resources to the municipalities (Collins et al., 2000). The system operates through three levels of government: the federal level, the states and the municipalities. Transfers are directly sent from the central government to the states and municipalities. The amounts are defined by constitution, being automatic and on a monthly basis (Transferências de Fundo a Fundo) and are mostly intend to finance primary care.

Another source of primary health care is the Family Health Program ( Programa Saúde na Familia), introduced by the municipal health secretariats in collaboration with the states and the Ministry of Public Health. The federal government supplies technical support and transfers funding through (Piso de Atenção). These sums are made up of a fixed and variable amount. The fixed amount is based on a per capita system and it is also designed to cover basic care. It includes health education, immunization, nutritional care, consultation with the doctor in basic specialities, dentist basic attention, home visits by nurse or community health worker, basic emergencies, minor operations in addition to ante-natal care, family planning activities and birth at home by a Family Doctor. The federal level can also make discretionary allocations based on requests from the municipalities. The actions financed by these resources are: basic medical and dental care, visits and outpatient care and home care Health Program (Programa Saúde na Família - PSF), vaccination, educational activities to community groups, prenatal care and home-birth, family planning activities, minor surgery, activities of community health and responsiveness in primary care unit. This implies that the role of policies, and in particular of municipal policies, is a very relevant determinant of health outcomes. ${ }^{15}$

In order to capture short term effects of having a female mayor on health care policy at the local level we exploit data from the Information System on Live Births (SINASC). ${ }^{16}$ This

transfers in the total amount of infrastructure transfers is calculated by using the average for these years (2003-2008).

${ }^{15}$ The fact that Fujiwara (2010) finds that political factors (i.e. voting technology) matters for infant care provision is indirect evidence that these outcomes are very sensitive to short term policies.

${ }^{16}$ Bhalotra and Clots-Figueras (2012) is a paper contemporaneous and independently started from ours 
system is managed by the Department of Health Situation Analysis, the Secretariat of Health Surveillance, in conjunction with State and Municipal Health Secretariat. Each State Health Department collects data on live birth certificates in healthcare facilities and on the registries (for home births), inputting information into the SINASC. When the collection is completed, the database is sent to the Ministry of Health which assembles the data. Therefore this data set contains monthly information on number of prenatal visits, period of pregnancy (weeks). The variable we are employing for this analysis is the share of pregnant women without prenatal visits and births that are not considered as premature (at least 37 weeks).

\subsection{Measuring corruption}

In April 2003 the Brazilian central government launched an anti-corruption program that aims to inhibit corruption at the local level. ${ }^{17}$ Since then, municipalities have been randomly selected by lottery to be audited. In the first three years of the program (2003, 2004 and 2005), the lotteries occurred mostly on a bimonthly basis. In the following years the intervals of the frequency of these lotteries were larger. During the lottery event members of the government, the media, and the public society are present. The first lottery was a pilot project where only five municipalities were selected to be audited, one for each Brazilian macro-region. The second lottery randomly selected 26 municipalities. Between the years 2003 and 2004, each lottery contained 50 municipalities that were randomly selected, and after October 2004, 60 municipalities per lottery. To date, the total number of municipalities audited is around 2,000 .

Corregedoria Geral da União - CGU is the body that conducts the audits. A couple of weeks after the lottery event, auditors are sent to the municipalities to examine the allocation of federal transfers. Audit event lasts two weeks. During this period, auditors examine the allocation of federal transfers. They collect documents and information from two years prior to the audit year to the present. A few months after the audit event, audit reports are sent to all levels of governments and are also made available to the public on the CGU Web site. Each report contains information about the total amount of federal transfers audited and full details of irregularities. Many types of irregularities are detected by the audits. Illegal

that looks at the relationship between child mortality and gender of the politician. See also Clots-Figueras (2012) on the relationship between education and the gender of the politician.

${ }^{17}$ This subsection relies heavily upon Brollo et al.(2012). 
procurement practices, diversion of funds, over-invoicing of goods and services, and fraud are the most common occurrences. We classify each occurrence in the audit reports in the spirit of Ferraz and Finan (2008), Brollo (2011) and Brollo et al. (2012).

The main categories of irregularities described in the audit reports are: illegal procurement practices, occurring when one of these episodes are reported: a) competition has been limited, for example, when associates of the mayor's family or friends receive non-public information related to the value of the project, b) manipulation of the bid value, c) irregular firm wins the bid process, d) the minimum number of bids is not attained, or e) the required procurement procedure is not executed; 2) fraud; 3) over-invoicing, occurring when there is evidence that public goods or services are purchased for a value above the market price; and 4) diversion of funds.

We classified irregularities in each of these categories using audit reports for municipalities in the first 28 lotteries. ${ }^{18}$ Our definition of corruption is a dummy variable that indicates whether at least one episode of any irregularity described above is detected by auditors (similar to Brollo et al, 2012).

\section{Empirical Strategy}

\subsection{Identification: Regression Discontinuity}

Identifying the effects of gender on policy outcomes is a daunting task. A comparison between municipalities with a male mayors and those with a female mayor will probably generate biased estimates due to endogeneity issues. For instance, local policies might be correlated with municipalities specific characteristics such as attitudes towards women or demographic characteristics and all of which could drive the results. Define $\tau_{i, t}(1)$ as the potential outcome of municipality $i$ if the mayor is a man, and $\tau_{j, t}(0)$ as the potential outcome of the same municipality if the mayor is a woman, in a specific time period $t .^{19}$ We are interested in estimating the difference in potential outcome in mixed-gender race,i.e. $E\left(\tau_{i, t}(1)-\tau_{i, t}(0) \mid j \in\right.$ $\Omega$ ). The problem of causal inference is that, at a given point in time, we cannot observe

\footnotetext{
${ }^{18}$ We are not considering the first lottery (pilot project) that selected only five municipalities. We have collected information in the audit reports of all municipalities selected from the $2^{\text {nd }}$ up to the $29^{\text {th }}$ lottery.

${ }^{19} \mathrm{In}$ our equations, $t$ is year or term depending on whether we have data for our outcome at the year or at the term level.
} 
both potential outcomes. That is, it is impossible to know the outcomes that a city that has a female mayor would have had with a male mayor. The intuition of our identification strategy is that cities in which a man won against a woman by a narrow margin can be a good counterfactual for those in which a female candidate won against a male candidate during a contested election.

The variable $M_{i t}$ defines the treatment status: $M_{i t}=1$ if the mayor is a man, and $M_{i t}=0$ otherwise. For a municipality, the probability of receiving a treatment has a sharp discontinuity equal to 1 at the threshold $M V_{i}=0$.

The observed outcome is thus: $\tau_{i t}=M_{i t} \cdot \tau_{i t}(1)+\left(1-M_{i t}\right) \cdot \tau_{i t}(0)$. The estimand of interest is the ATE, $E\left[\tau_{i t}(1)-\tau_{i t}(0)\right]$, defined over some subpopulation of interest.

Specifically, we define the treatment group as the municipalities that have a mayor who is man in a mixed-gender race. Assignment to treatment can be formalized as:

$$
\text { Male }_{i t}=1\left[M V_{i t} \geq 0\right]
$$

where $M V_{i t}$ is the male candidate margin of victory in municipality $i$ during term $t$ and 1[.] the indicator function. It is specified as the difference between the vote share of the male vote minus the vote share of the female candidate, meaning it will have positive values if the mixed-gender electoral race resulted in a male mayor. This measure is thus greater than zero in municipalities where the mayor is man, and lower than zero otherwise. At the zero threshold, $M V_{i t}=0$, the gender of the mayor $M_{i t}$ sharply changes from zero to one.

$M V_{i t}$ can be seen as a random variable depending on observable and unobservable variables, as well as on random events on election day. The standard RDD assumption is that potential outcomes must be a continuous function of the running variable at the threshold (Hahn, Todd, and Van der Klaauw, 2001). We will test this assumption in section 5.4. ${ }^{20}$

The ATE in close elections is thus:

$$
\gamma_{p e r} \equiv E\left[\tau_{i t}(1)-\tau_{j t}(0) \mid M V=0\right]=\lim _{M V \downarrow 0} Y-\lim _{M V \uparrow 0} Y
$$

$\gamma_{p e r}$ is defined as local effects, because it captures the impact of the gender of the mayor on corruption only for towns around the threshold $M V=0$ (i.e. for the elections that were decided for a margin that is tiny enough).

\footnotetext{
${ }^{20}$ It should be noted that the assumptions refer to the potential outcomes. The actual outcome will be only one, of course, and if gender plays a role in affecting corruption it will also be discontinuous at $M V=0$.
} 


\subsection{Estimation}

We first describe whether gender is correlated to our outcomes by estimating the following OLS equations:

$$
\tau_{i t}=\rho_{0}+\rho_{1} M_{i t}+\mu_{t}+\eta_{i t}
$$

where $\tau_{i t}$ is the outcome of interest in city $i$ in time period $t, M_{i t}$ is a dummy that is one when the mayor of the city is a man, $\mu_{t}$ are year fixed effects and standard errors are clustered at the city level because the same municipality may be observed in repeated mayoral terms. ${ }^{21} \mathrm{We}$ report coefficient $\hat{\rho_{1}}$, that does not have a causal interpretation because the gender of the politician might be correlated with the error term. ${ }^{22}$

We then use two different methods to estimate the ATE expressed in equation (2). First, we apply a spline polynomial approximation, that is, we fit a $p$-order polynomial in $M V_{i t}$ on either side of the threshold $M V_{i t}=0$ :

$$
\tau_{i t}=\sum_{k=0}^{p}\left(\rho_{k} M V_{i t}^{k}\right)+M_{i t} \sum_{k=0}^{p}\left(\pi_{k} M V_{i t}^{k}\right)+\mu_{t}+\eta_{i t},
$$

where $M V$ is the margin of victory and standard errors are clustered at the town level The estimated coefficient $\hat{\pi}_{0}$ identifies the ATE at the threshold. ${ }^{23}$

We then we follow Imbens and Lemieux (2008) and use a local linear regression approach, which restricts the sample to municipalities in the interval $M V_{i t} \in[-h,+h]$ and estimates the model:

$$
\tau_{i t}=\rho_{0}+\rho_{1} M V_{i t}+\delta_{0} M_{i t}+\delta_{1} M_{i t} \cdot M V_{i t}+\mu_{t}+\eta_{i t}
$$

where standard errors are clustered at the town level, and $\hat{\delta}_{0}$ identifies the ATE at the zero threshold.

Finally we check for treatment effect heterogeneity in separate subsamples. The intuition for this test is simple. Assume that $D_{i t}$ captures a given heterogeneity dimension, which in

\footnotetext{
${ }^{21}$ It should be noted that we can include year fixed-effects only when we have yearly data for the outcome of interest.

${ }^{22}$ For example, this would happen if places that are more tolerant toward women are more likely to elect female mayors.

${ }^{23}$ While the benefit of this estimation strategy is the possibility of keeping the whole sample, the cost is that results might potentially be sensitive to outcome values for observations far away from the threshold (see Imbens and Lemieux, 2008). We follow the standard procedure of fitting a third order polynomial. We computed our results with lower or higher order polynomials (i.e. identifying the effect on observations respectively farther and closer to the threshold) and our results are robust to different specifications. Results are available upon request).
} 
our case is term limit. We estimate:

$$
\begin{array}{r}
\tau_{i t}=\sum_{k=0}^{p}\left(\rho_{k} M V_{i t}^{k}\right)+M_{i t} \sum_{k=0}^{p}\left(\pi_{k} M V_{i t}^{k}\right)+ \\
+D_{i t} \cdot\left[\sum_{k=0}^{p}\left(\alpha_{k} M V_{i t}^{k}\right)+M_{i t} \sum_{k=0}^{p}\left(\beta_{k} M V_{i t}^{k}\right)\right]+\xi_{i t} .
\end{array}
$$

As a result, $\hat{\pi}_{0}$ identifies the treatment effect in $D_{i t}=0, \hat{\pi}_{0}+\hat{\beta}_{0}$ in $D_{i t}=1$, and $\hat{\beta}_{0}$ the difference between the two. The interpretation of the difference between the two subsamples should not be interpreted as causal.

\section{Results}

\subsection{Sample selection and descriptive statistics}

Brazil has currently 5,567 municipalities. Our study encompasses all municipalities for which we have non missing outcomes data and with mixed gender races in two elections: October 2000 and October 2004. During those terms, mayors are in office for four years, i.e. from 2001 to 2004 and from 2005 to 2008, respectively.

In order to implement our identification strategy in the Brazilian multi-party system along the lines discussed in the previous Section, we restrict our sample to two candidates elections where one candidate is a woman and the other is a man. ${ }^{24}$ This sample selection procedure improves internal validity, but as all RDD set up, it comes at the price of lower external validity. The races with only two candidates amount to $51 \%$ of the total. If we further restrict the sample to elections where we have two candidates of different gender, we end up with a sample of two-candidate races that covers $7 \%$ of the races in each term.

There are 723 elections that match our definition of mixed gender races and for which we don't have missing data for health and transfers outcomes. To evaluate the external validity with the RDD sample selection, we can look at how the above subsamples differ from the rest of Brazilian municipalities. In Table 1 we compare the elections in our sample versus

\footnotetext{
${ }^{24}$ We only consider two candidates elections because the majority of candidates are men. This generates a discontinuity of the density of the running variable when considering close elections with more than two candidates. As a result, the assumption of the continuity of the density is not satisfied in any other subsample of our data. For example, the discontinuity of the log-density of our running variable for the elections with three candidates is estimated in 0.152 with a standard error of 0.086. Additional results available upon request.
} 
the rest of Brazilian elections. As we can see, in our sample, among other things, races are more likely to happen in smaller and poorer cities. In Table 2 we do a similar exercise for our outcomes.

The results of balance tests for municipal and mayoral characteristics are reported in Table $3{ }^{25}$ In this Table we check whether observable covariates are unbalanced between female and male politicians. If, for example, men were more likely to face a binding term limit, this would imply that our estimates could potentially reflect the effect of this difference. We can see that all of our observable covariates are balanced in close elections, suggesting that men and women's observable characteristics converge in close elections. Our dataset allows to test a vast array of observable variables, including geographic location of the city (first row of the Table), town's characteristics, such as income and population, and, most importantly, many individual level covariates such as party affiliation or education. It's particularly interesting that even the gender city level wage gap is balanced across our threshold. This variable is computed using micro data from the 2000 Brazilian demographic census. We estimate, for each Brazilian municipality, whether the log of the hourly wage is affected by observable characteristics (gender, age, residence region, education, occupation and race). The gender coefficient obtained in these regressions is our measure of gender gap. This check suggests that labor market conditions that affect the equilibrium wage gap, such as discrimination (on the supply side), or selection (on the demand side) are balanced around the cutoff in our sample of municipalities.

The credibility of these balance tests is reinforced by visual inspection. Figures 1, 2, 3, and 4 illustrate scatterplots of the mean of these variables. In these graphs we plot respectively the average of our municipal and mayoral characteristics for cities in which women won (at the left of the zero) and in those where men won (at the right of the zero). The variable on the $\mathrm{x}$-axis is the margin of victory, and the observations are averaged within bins of 2.5 percent of margin of victory. Given the density of the margin of victory is concentrated in close elections, it should be noted that points closer to the zero are both more relevant for our strategy and contain more information compared to those far from the zero margin of

\footnotetext{
${ }^{25}$ Note that we perform these balance tests by applying a spline polynomial approximation. We also did the same check by applying a local linear regression and we find identical results. Results are available upon request.
} 
victory. ${ }^{26}$ As these variables are predetermined with respect to the gender of the mayor, we should observe no discontinuity, as long as there is no manipulative sorting around the zero threshold. This is indeed the case, as all of the variables are balanced around the threshold. ${ }^{27}$

\subsection{The Effects of a Female Candidate Winning a Mixed Gender Close Election}

Our main results are reported in Table 4, which shows the estimates for the impact of gender on the ability to attract infrastructure transfers, health care outcomes and corruption.

For all outcomes we report results for OLS and three different specifications for the RDD estimates. We report our baseline results from a split third order polynomial specification which considers the entire mixed gender sample. Then, the results for local linear regressions with optimal and half-optimal bandwidth. ${ }^{28}$

Columns 1, 2 and 3 report the results for total, discretionary and non-discretionary infrastructure transfers, respectively. According to our estimates, women attract significantly higher infrastructure transfers for their municipalities. Note that the results on total infrastructure transfers are driven from discretionary infrastructure transfers. As a falsification test, in column 3 we estimate our equations for non-discretionary infrastructure transfers. It is reassuring that gender does not seem to be related to the non discretionary component of transfers. According to our baseline results (third order polynomial specification), men attract around from 65 to 55 percent less discretionary infrastructure transfers than their female counterparts, depending on the empirical specifications. It is remarkable that the magnitude of the effect is similar if we use local linear regression or the polynomial specification.

Given that in the Brazilian institutional setting the ability of the mayors to negotiate with the federal government is one of the main determinant of the size of discretionary

\footnotetext{
${ }^{26}$ See Figure 7.

${ }^{27}$ It is particularly interesting to note that we find convergence in close elections also for the observables that don't seem to be balanced for elections that are not close. For example, as can be seen from the graphs of the educational variables, female mayors are on average substantially more educated than their male counterparts. This finding is consistent with what Gagliarducci and Paserman (2012) find for Italian politicians, and it is also consistent with what Goldin, Katz and Kuziemko (2009) find recently for American College Women. However, in close elections even those educational variables do converge together and the jump is not statistically significative.

${ }^{28}$ We compute optimal bandwidth with the algorithm by Imbens and Kalyanaraman (2009).
} 
transfers, we interpret our findings as consistent with the conclusions of the gender and negotiation literature. For example, Bowles, Babcock and McGinn (2005) argue that women work harder than men when negotiating on behalf of others. The authors note that female executives perform better than male executives when bargaining for the compensation of someone they had mentored. However, it should be noted that many others interpretations are possible. A second alternative interpretation is related to the role of the President. It's possible that the President, for political or economic reasons, favors women in the process of allocating the funds. A third possibility is that women put relatively more effort into applying to those transfers in case they have higher electoral incentives than men. In the following subsection we will show evidence that is more consistent with the first two explanations and less consistent with the third explanation.

Columns 4 and 5 report the results for our health care outcomes: percentage of women who did not attended any pre-natal visits and percentage of births in which the baby was not born pre-mature. Our RDD estimates show us that in municipalities headed by female mayors, the percentage of women without any pre-natal visits goes down. Moreover, in these municipalities, the probability of a pre-mature birth is relatively lower. According to our split polynomial specification, we find that the share of pregnant women without any prenatal visits increases by $1.6 \%$ (or $60 \%$ of the sample mean) when a man wins a close election against a woman. Additionally, we find that the regular births (i.e. the not premature ones) reduce by $1.2 \%$ (or $1.3 \%$ of the sample mean)when a man wins a close election against a woman. ${ }^{29}$ There are many interpretations for these results. One possibility is that women mayors are monitoring closer the (given) health resources allocated to a municipality, assuring that prenatal care is provided as effectively as possible. An alternative interpretation is that women attract more spending and this makes easier to provide health care for all the pregnant women. Ideally, in order to distinguish between these two alternative channels, we would need to obtain data on the quality of the public health spending, and on the proportion of discretionary transfers that are allocated to health infrastructure. To the best of our knowledge, for the period of the analysis, there are no data on quality of public health spending or proportion of infrastructure transfers allocated to health infrastructure projects.

\footnotetext{
${ }^{29} \mathrm{~A}$ third outcome that can be analyzed from our dataset is babies' birthweight. We find that this outcome is not affected by the gender of the policymaker. Results are available upon request.
} 
Distinguishing between these two possible channels is beyond the scope of this paper, and it is left for future research.

The outcomes for regressions reported in columns 6 and 7 come from the audit reports. The dependent variable in column 6 is whether the mayor is found to be involved in any irregularity classified as corruption (overall corruption). The outcome variable for regressions displayed in column 7 is whether the mayor is involved in any episode of illegal procurement practice - a relevant category of irregularities where the mayor play a direct important role. Note that for these regressions we can use only the sample of audit municipalities. The intersection between the audited sample and the mixed gender elections will reduce the sample size in this part of the paper.

According to the results men seem to grab relatively more rents than women, on average. The size of the effect ranges from $33 \%$ to $38 \%$ and from $18 \%$ to $33 \%$ in columns 6 and 7 , respectively. Despite the limited sample size, note that we obtain similar magnitudes of coefficients in most specifications. It is also reassuring that this data is obtained from a random sampling procedure, given that the Brazilian Audit Reports Program randomizes the auditing process. These results as potentially consistent with the view that female mayors affect our health outcomes of interest not only though attracting more resources or spending more on health, but also through better managing at a given amount of resources by implementing more transparent and legal policies.

Visual inspection of the outcomes in Figure 5 corroborates the previously discussed results. In the figure we average our outcome into bins of intervals of the margin of victory. It should be noted that the bins closer to our threshold contain more observations, given that the density of elections is concentrated around close ones.

In Table 5 we look at the effect of gender in close elections on the probability of re-election and the probability of re-running. We find that a man who wins a close election against a woman is around 20 percentage points more likely to be reelected, out of a baseline mean of 40 percent. The coefficient for the RDD specifications is stable, and we loose statistical significance in the last specification (half optimal bandwidth) only because of the reduced sample size. In column (2) we show that the decision of re-running is not affected by the gender resulting in a close election. ${ }^{30}$ This finding is corroborated by visual inspection of

\footnotetext{
${ }^{30}$ It is important to note that, even if male mayors after a mixed gender close election are more likely to
} 
Figure 6. This effect is particularly surprising, especially in light of the previously discussed findings, where we showed that women provide better outcomes and attract more resources.

In order to shed light on this puzzle, we analyze data on public employees. We present our results in Table 6. We look at two dependent variables, i.e. the temporary public employees hired by the local administration during the electoral year, and the permanent public employees. ${ }^{31}$ We find that men that win a mixed gender close election hire from 65 to 75 more temporary public employees, out of a baseline mean of 67 temporary public employees, compared to their female counterparts. ${ }^{32}$ We don't find a statistically significant difference for permanent public employees. This finding might potentially help to explain why men are more likely to be reelected in spite of their worst performance in attracting infrastructure transfers and in pre-natal care provision. While the latter outcome can generally be thought as general-interest outcomes, that benefit a wide set of the constituency, hiring more temporary public employees might be a policy more related to special-interest groups. On the one hand, general interest policies such as caring about infants are likely to benefit the majority of voters, and thus in principle might help the incumbent to be reelected. On the other hand, concentrated interests are usually better organized than diffuse ones (Olson 1965, Wilson 1980). According to this view, special-interest policies might potentially help re-election seeking politicians. To the extent to which hiring public employees can be interpreted as a special-interest policy with respect to improving prenatal care provision or putting effort into attracting more public investments, this evidence suggests that the men in our sample might be potentially target short-term policies that help them get reelected and extract rents, rather than optimizing the welfare of their constituency.

Overall, for most of our empirical results, the size of the effect of gender in the RDD

be reelected, this does not imply that male mayors that were elected during a close election are more likely to be in a second term. Our outcome "Probability of re-election" refers to the election subsequent to the mixed gender close election. This means that the margin of victory of the incumbent mayor in the subsequent elections or the gender of the opponent are most likely different. On the other hand, the variable on which we implement the balance test refers on a second term during the current election. The latter is balanced, as shown in the graph in the bottom right of Figure 3 .

${ }^{31}$ Data on the number of public employees in the municipal administration comes from the survey Perfil dos Municipios Brasileiros 2004 and 2008.

${ }^{32}$ It should be noted that the size of the effect is not robust when we reduce the bandwidth to the half of the optimal one. This is probably due to the fact that we have many missing variables for this outcome, and the optimal bandwidth for this variable is already relatively small $(9 \%)$. This implies that the sample size for the half optimal bandwidth specification is probably too small ( 87 observations) to draw any conclusion. 
estimations is somehow larger and more significant than the effect in the OLS estimation. The reason could be at least twofold: on one hand, the RDD setup controls for unobservables city-specific confounding factors, removing omitted bias; on the other hand, the RDD effect is identified off close electoral races only, where politicians might have different incentives to implement particular policies compared to cities without closely contested races, and competition might exacerbate per se gender differences, as noted by Niederle and Vesterlund (2007). ${ }^{33}$

\section{$5.3 \quad$ Heterogeneities}

One interesting exercise that we are able to complete due to the richness of the Brazilian births data is by disentangling the effect we find for our prenatal care outcomes by educational level of the mother. Panel A and B in Table 7 repeat our analysis for each separate educational category respectively for the pre-natal visits and the pre-mature births. Consistently with Fujiwara (2010), we find that the effect of policies on health outcomes are concentrated on less educated mothers.

In order to shed light on whether re-election incentives differentially affect mayors of different genders, we report the results for treatment effect heterogeneity by exploiting term limits for mayors in Brazil. See the specification in equation (6) and results are displayed in Table 8. Column 1, 2 and 3 report the results when the dependent variables are temporary public employee, no pre-natal visits and discretionary infrastructure transfers, respectively. ${ }^{34}$ We notice that male local politicians hire more public employees only when compared to female politicians in their first term. Additionally, cities governed by men are characterized by more women who don't attend any pre-natal visit only when local governors are in their second term. The results for temporary public employment and pre-natal visits suggest that men react to electoral incentives. Note that this set of results, and in particular the hiring

\footnotetext{
${ }^{33}$ Our empirical strategy is able to control for unobservable city-specific confounding factors, but it is still possible that some individual level characteristics are correlated with the gender of the mayor. While we acknowledge the limitation, that is probably the challenge for this literature, we believe that is reassuring that all of our individual level observable variables converge in close elections, as confirmed by visual inspection of Figures 3, and 4.

${ }^{34}$ re-election outcomes are by construction available only for mayors in their first term, because of the Brazilian two-term-limit legislation. Hence we can't perform this exercise on those outcomes. We can not reach any conclusion for the non premature births outcome, given that coefficients are too imprecisely estimated and are not significative in both subsamples. Results available upon request.
} 
of public employees before the election, might potentially rationalize the finding that men that win a close election against a woman are more likely to be reelected. First, there is the direct channel of rewarding a politician providing public jobs. Second, these new public employees might be directly involved in tasks related to electoral campaign of the incumbent.

The results for pre-natal visits seem to be driven by lame duck mayors, suggesting that men deliver worst outcomes compared to women particularly when male mayors do not have reelection incentives. On the other hand we find that female mayors receive relatively more infrastructure transfers in both first and second term. To the best of our knowledge, this is one of the first attempts in the literature to try to understand whether intrinsic preferences or electoral incentives are at the base of gender differences. We are aware that sample size and is limiting the strength of our conclusions, but this approach can potentially be used in different settings to analyze more deeply the causes of gender differences in political behavior that has been documented now in many different institutional settings. We are also aware that these findings should be interpreted with caution since term limits may bind for different groups of male and female politicians, due to gender differences in voter's preferences for incumbents. Although it is also reassuring the fact the observable covariates are balanced around the cut-off within those two subsamples.

\section{$5.4 \quad$ Validity tests}

The validity of our RDD relies on the fact that political candidates should not be able to manipulate electoral outcomes in close elections. If, for example, men are able to manipulate the results of close elections in their favor, selection would still alter our estimates. First, we can check for nonrandom sorting by visually inspecting the histogram of the margin of victory (see Figure 7 ). We can see that there are no clear spikes at the right or the left hand side of the discontinuity. Additionally, we address the concern of nonrandom sorting by formally testing the continuity of the density of the margin of victory, following McCrary (2008), in Figure 8. This procedure tests the null hypothesis of continuity of the density of the margin of victory at the zero threshold, and it is implemented by running kernel local linear regressions of the log of the density separately on both sides of zero. 


\section{Conclusion}

In this paper we provide new evidence about the effect of the gender of the policymaker on policy outcomes after a close election. Our empirical strategy allows us to control for unobservables city-specific confounding factors. We find that female mayors in our sample attract more discretionary transfers, provide more pre-natal health, and are less corrupt than male mayors in mixed close races. In spite of this, we find that men are more likely to be reelected. We discuss several potential explanations, including the role of re-election incentives and political patronage. These are several interpretations that can be consistent with our results. One interpretation is that women have preferences that are more socially oriented compared to men, consistent with some evidence from the lab such as Andreoni and Vesterlund (2001). Another interpretation for these results is that women and men react differently in situations characterized by a high degree of competition (for example, Niederle and Vesterlund, 2007). Another possible interpretation, related to Bowles et al. (2005), is related to gender differences in behaviors when it comes to representing other people's interests.

Our results raise a number of questions for further research. First, we identified our local average treatment effect on the subset of women who are running against a man in a close election. This effect is of particular interest when thinking about the policy effects of naturally increasing women's participation in electoral races, but is of less interest when trying to understand whether the introduction of female quotas in politics would improve representation of women and would affect policy outcomes. ${ }^{35}$ We think that the political reservations strategy by Chattopadhyay and Duflo (2004) is more suited for answering to the latter question. We believe that it is an exciting direction for future research to understand which policy is the optimal one to achieve more equality in politics and in leadership situations. ${ }^{36}$

\footnotetext{
${ }^{35}$ Today women occupy 13 percent of the seats in the lower houses of parliament in Latin America. The region ranks behind Northern Europe (39 percent), and is comparable with the world average, as well as the United States (13\%), see Htun and Jones (1999). The quota system for female candidates in the lower house of representatives was implemented in Brazil in 1995 but with no success. In the 2006 federal elections, only 12,6 percent of the candidates running for the lower house were women and in 2010, 19,2 percent of them were female.

${ }^{36}$ For example, even though quotas will be certainly more effective in achieving a specific numerical representation in a short span of time, there can be unintended costs (Pande and Ford, 2011).
} 
Secondly, we are able to identify our effect in close elections, characterized by an high degree of competition. Competition might per se enhance gender differences. For example, Gneezy et al. (2003) and Niederle and Vesterlund (2007) find that competitive situations might have a gender-differentiated effect. A rapidly growing literature is making political competition an endogenous variable that can be chosen to maximize voters' welfare (Caselli et al., 2012).

Thirdly, it is unclear whether our results will be externally valid in countries with different attitudes toward women compared to Brazil. Culture has recently become an area of active economic research. Recent findings in the economics of culture suggest pathways through which attitudes toward women may affect policies (Beaman et al., 2009 or Givati and Troiano, 2012). Policymakers may benefit from explicitly accounting for those slowmoving constraints, and understanding the circumstances under which values and beliefs can be affected.

\section{$7 \quad$ References}

Alesina, A. (1988): "Credibility and Policy Convergence in a Two-Party System with Rational Voters," American Economic Review, 78: 796-806

Ames, B., (1995): "Electoral Strategy under Open-List Proportional Representation," American Journal of Political Science, 39 (2): 406-433

Andreoni, J., Vesterlund, L. (2001). "Which is the fair sex? Gender differences in altruism" Quarterly Journal of Economics 116, 293-312.

Anzia S. and C. Berry (2011): "The Jackie (and Jill) Robinson Effect: Why Do Congresswomen Outperform Congressmen?," American Journal of Political Science, 55 (3): 478493

Barro, R.J., (1973): "The Control of Politicians: An Economic Model," Public Choice, 14, $19-42$.

Beaman, L., R. Chattopadhyay, E. Duflo, R. Pande, and P. Topalova (2009): "Powerful 
Women: Does Exposure Reduce Bias?," Quarterly Journal of Economics, 124(4), 14971540.

Bertrand, M. (2011): "New Perspectives on Gender," in Orley Ashenfelter and David Card eds, Handbook of Labor Economics, v. 4b.

Bertrand M., C. Goldin and L. Katz (2010): "Dynamics of the Gender Gap for Young Professionals in the Financial and Corporate Sectors," Marianne B., C. Goldin, and L. F. Katz American Economic Journal: Applied Economics, 2(3): 228-55

Bertrand, M. and Hallock, K. F. (2001): "The Gender Gap in Top Corporate Jobs", Industrial and Labor Relations Review, 5: 3-21

Bhalotra S. and I. Clots-Figueras (2012): "Health and the Political Agency of Women ", working paper

Bowles, H.R., Babcock, L., McGinn, K. L. (2005): "Constraints and triggers: Situational mechanics of gender in negotiation" Journal of Personality and Social Psychology, 89:951965.

Brollo F. (2011): "Who Is Punishing Corrupt Politicians - Voters or the Central Government? Evidence from the Brazilian Anti-corruption Program", Mimeo.

Brollo F. and T. Nannicini (2012): “Tying Your Enemy's Hands in Close Races: The Politics of Federal Transfers in Brazil," American Political Science Review, forthcoming

Brollo, F., T. Nannicini, R. Perotti, and G. Tabellini (2012): "The Political Resource Curse," American Economic Review, forthcoming

Caselli, F., T. Cunningham, M. Morelli and I. Moreno de Barreda (2012): "Signalling, incumbency advantage and optimal re-election thresholds", NBER working paper

Chattopadhyay, R. and Duflo, E. (2004): "Women as Policy Makers: Evidence from a Randomized Policy Experiment in India" Econometrica, 72: 1409-1443

Clots-Figueras, I. (2012): "Are Female Leaders Good for Education? Evidence from India" Mimeo, American Economic Journal: Applied Economics, 4(1), 212-44 
Collins, C., J. Araujo and J. Barbosa (2000): "Decentralizing the health sector: issues in Brazil," Health Policy, 52: 113-127

De Paola, M. ,V. Scoppa and R. Lombardo (2010), "Can gender quotas break down negative stereotypes? Evidence from changes in electoral rules", Journal of Public Economics Volume 94, Issues 56, June 2010, Pages 344-353

Doepke M., M. Tertilt and A. Voena (2011): "The Economics and Politics of Women's Rights", working paper

Dollar, D., R. Fisman and R. Gatti (2001): "Are Women Really the Fairer Sex? Corruption and Women in Government" Journal of Economic Behavior and Organization, 46: 423429 .

Duflo, E. (2011): "Women Empowerment and Economic Development," working paper

Eckel C. and P. Grossman, (2008): "Differences in the Economic Decisions of Men and Women: Experimental Evidence," Handbook of Experimental Results, edited by C. Plott and V. Smith. New York, Elsevier

Eagly, A.H. (1987): "Sex differences in social behavior: A social-role interpretation," NJ, England: Lawrence Erlbaum Associates, Inc. xii

Edlund, L., and R. Pande (2001): "Why Have Women Become Left-Wing? The Political Gender Gap and the Decline in Marriage," Quarterly Journal of Economics, 117: 917-961

Engerman, S. L., and K. L. Sokoloff (2002): "Factor Endowments, Inequality, and Paths of Development among New World Economies," Economia, v. 3.

Ferraz, C. and F. Finan (2008): "Exposing Corrupt Politicians: The Effects of Brazil," Publicly Released Audits on Electoral Outcomes," Quarterly Journal of Economics, 123: 703-745

Ferraz, C. and F. Finan (2011): "Electoral Accountability and Corruption: Evidence from the Audits of Local Governments," 101 (4): 1274-131 
Ferraz, C. and F. Finan (2009b): "Motivating Politicians: The Impacts of Monetary Incentives on Quality and Performance," NBER working paper $n_{o} 14906$

Ferreira, F., and J. Gyourko (2010): "Does Gender Matter for Political Leadership? The Case of U.S. Mayors," Wharton working paper

Field, E., Jayachandran, S., and R. Pande (2010): "Do Traditional Institutions Constrain Female Entrepreneurship? A Field Experiment on Business Training in India," American Economic Review 100(2): 125-129

Fréchette, G. R., F. Maniquet, and M. Morelli (2008), “Incumbents' Interests, Voters' Bias and Gender Quotas", American Journal of Political Science, Volume 52, Issue 4, October, pp. 891-909

Fujiwara, T. (2010): "Voting Technology, Political Responsiveness, and Infant Health: Evidence from Brazil," working paper

Fujiwara, T. (2011): “A Regression Discontinuity Test of Strategic Voting and Duverger's Law", Quarterly Journal of Political Science, 2011, 6: 197-233

Gagliarducci, S., and M. D. Paserman (2012): "Gender Interactions within Hierarchies: Evidence from the Political Arena," Review of Economic Studies, forthcoming

Givati, Y., and U. Troiano. (2012): "Law, Economics and Culture: Theory and Evidence from Maternity Leave Laws," Journal of Law and Economics, forthcoming.

Gneezy, U., Niederle, M., and A. Rustichini (2003): "Performance in Competitive Environments: Gender Differences," Quarterly Journal of Economics 118(3): 1049-1074

Goldin C., L. Katz and I. Kuziemko (2006): "The Homecoming of American College Women: The Reversal of the College Gender Gap", Journal of Economic Perspectives, 20(4): 133156.

Goldin, C, C. Rouse (2000): "Orchestrating Impartiality: The Effect of Blind Auditions on Female Musicians", American Economic Review, September 2000 
Htun, M.N. and Jones, M.P. (1999): "Engendering the Right to Participate in DecisionMaking: Electoral Quotas and Women's Leadership in Latin America," Unpublished manuscript.

Imbens, G. and T. Lemieux (2008): "Regression Discontinuity Designs: A Guide to Practice," Journal of Econometrics, 142: 615-635

Imbens, G. W., and Kalyanaraman, K. (2009): "Optimal Bandwidth Choice for the Regression Discontinuity Estimator," Working paper

Lavy, V. (2008): "Gender Differences in Competitiveness in a Real Workplace: Evidence from Performance-Based Pay Tournaments among Teachers," Mimeo, Hebrew University

Lee, David S. (2008): "Randomized Experiments from Non-random Selection in the U.S. House Elections" Journal of Econometrics, 142, 675-697

Mainwaring, S. (2002): "Presidentialism in Brazil: The Impact of Strong Constitutional Powers, Weak Partisan Powers, and Robust Federalism," The Latin American Program Working Paper Series.

McCrary, J. (2008): "Manipulation of the Running Variable in the Regression Discontinuity Design: A Density Test," Journal of Econometrics, 142: 698-714

Niederle, M., and Vesterlund L., (2007): "Do Women Shy away from Competition? Do Men Compete too Much?," Quarterly Journal of Economics, 122(3): 1067-1101

Niederle, M., and Yestrumskas, A. H. (2008): "Gender Differences in Seeking Challenges: The Role of Institutions" NBER Working Paper 13922

Norton, N. H. (1995): "Uncovering the Dimensionality of Gender Voting in Congress," Legislative Studies Quarterly, 24: 65-86

Nowell, C., Tinkler, S. (1994): "The influence of gender on the provision of a public good," Journal of Economic Behavior and Organization 25: 25-36

Olson, M. (1965): "The Logic of Collective Action: Public Goods and the Theory of Groups," Harvard University Press 
Pande, R., and D. Ford (2011): "Gender Quotas and Female Leadership: A Review". Washington DC: Worldbank.

Persson, T., and G. Tabellini (2000): Political Economics, Cambridge, MA: MIT Press.

Pino, F. (2011): "Is There Gender Bias Among Voters? Evidence from the Chilean Congressional Elections," working paper

Tollini, H. (2009): "Reforming the Budget Formulation Process in the Brazilian Congress," OECD Journal on Budgeting 9(1): 1-29

Samuels, D. (2002): "Pork Barreling Is Not Credit Claiming or Advertising: Campaign Finance and the Sources of the Personal Vote in Brazil," Journal of Politics 64(3): 845863.

Swamy A., S. Knack, Y. Lee and O. Azfar (2001): "Gender and Corruption", Journal of Development Economics, 64: 25-55.

Vega, A. and Firestone, J. M. (1995): "The Effects of Gender on Congressional Behavior and the Substantive Representation of Women" Legislative Studies Quarterly, 20: 213-222.

Vogl, T. (2012): "Race and the Politics of Close Elections", Unpublished manuscript.

Weyland, K. (1996): "Obstacles to Social Reform in Brazil's New Democracy," Comparative Politics 29(1): 1-22

Welch, S. (1985): "Are Women More Liberal than Men in the U.S. Congress?" Legislative Studies Quarterly, 10: 125-134

Wilson, J. (1980): "The Politics of Regulation," Wilson, James Q (ed.), The Politics of Regulation, New York, Basic Books: 357-447 


\section{Figures}

Figure 1: Balance tests - Municipal characteristics

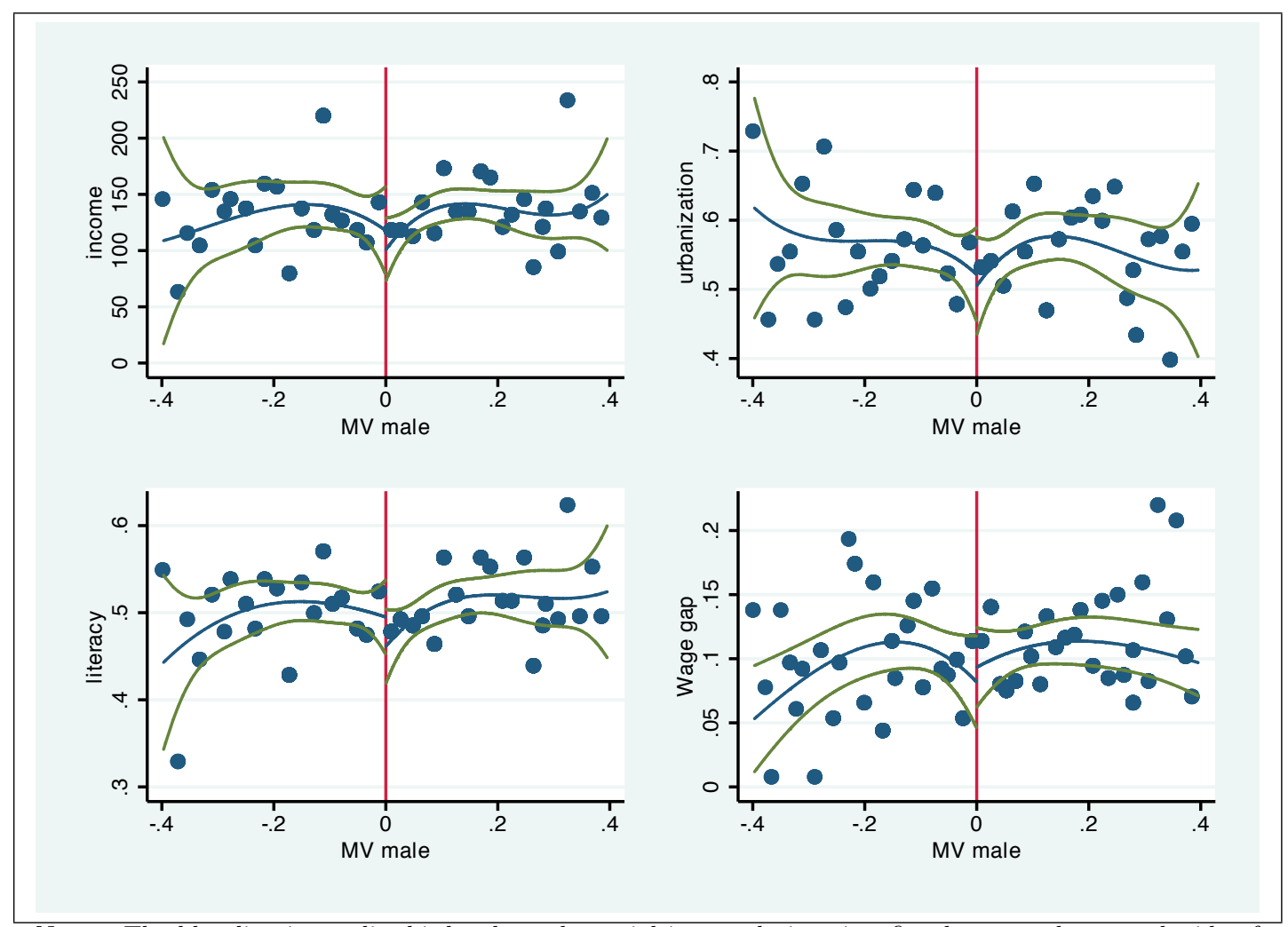

Notes. The blue line is a split third-order polynomial in population size, fitted separately on each side of the margin of victory (MV male) thresholds at zero (margin of victory is defined as greater than zero if the candidate that won is a male, lower than zero if the candidate that won is a female). The green lines are the 95 percent confidence interval of the polynomial. Scatter points are averaged over 2 percent intervals. Terms 2001-2005 and 2005-2008. Income refers to monthly per-capita income in 2000 and is measured in Brazilian reais. Urbanization is the fraction of people living in urban areas. Literacy rate is the fraction of people above 20 who are literate. Gender wage gap is the estimated gender salary gap, see paper for details about the estimation of this variable. 
Figure 2: Balance Tests - Municipal Characteristics
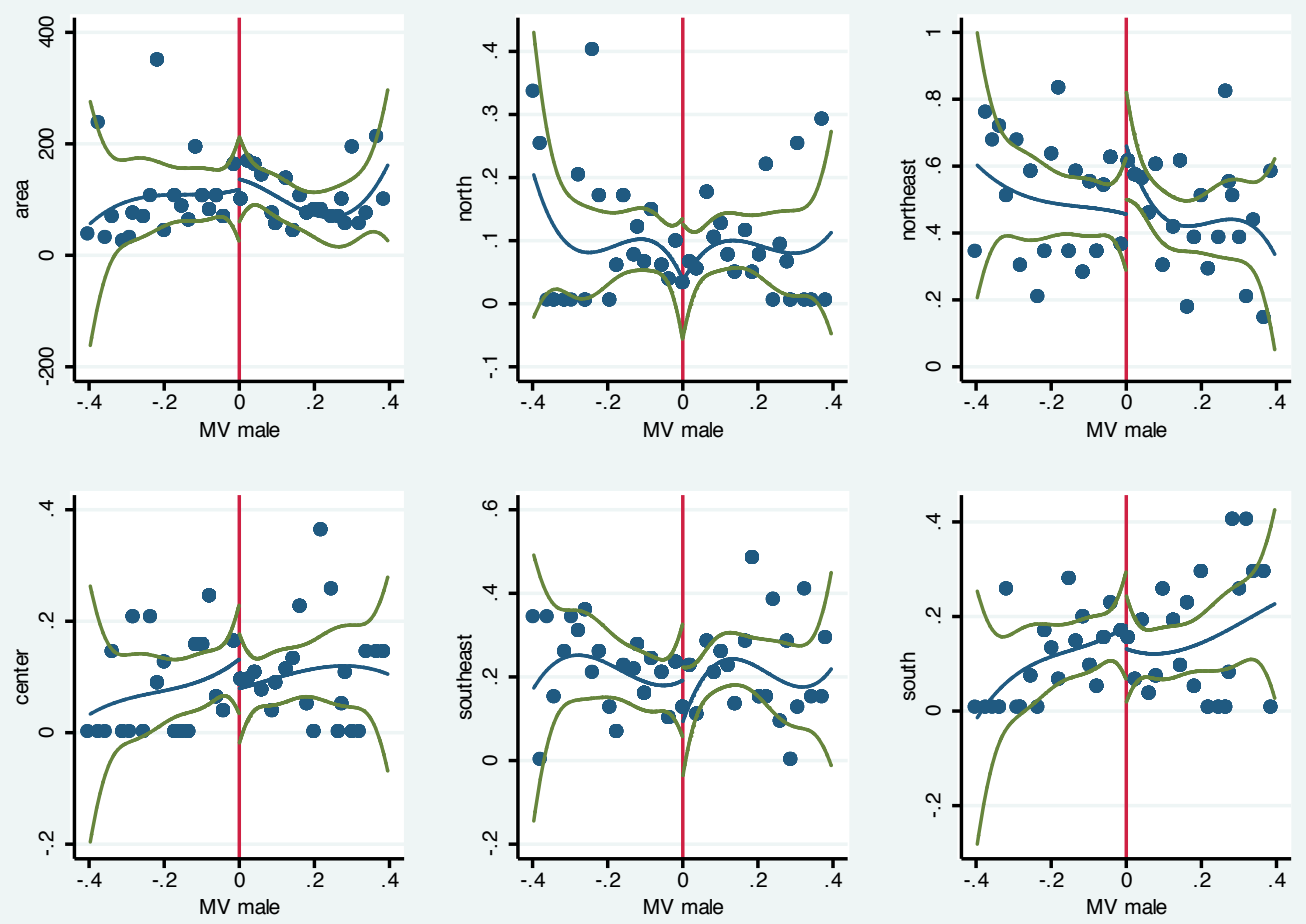

Notes. The blue line is a split third-order polynomial in margin of victory of the male candidate, fitted separately on each side of the margin of victory (MV male) thresholds at zero (margin of victory is defined as greater than zero if the candidate that won is a male, lower than zero if the candidate that won is a female). The green lines are the 95 percent confidence interval of the polynomial. Scatter points are averaged over 2 percent intervals. Terms 2001-2005 and 2005-2008. Area refers to the area size of the municipality. North, Northeast, Center, South, and Southeast are the Brazilian macro-regions. 
Figure 3: Balance Test - Mayoral Characteristics
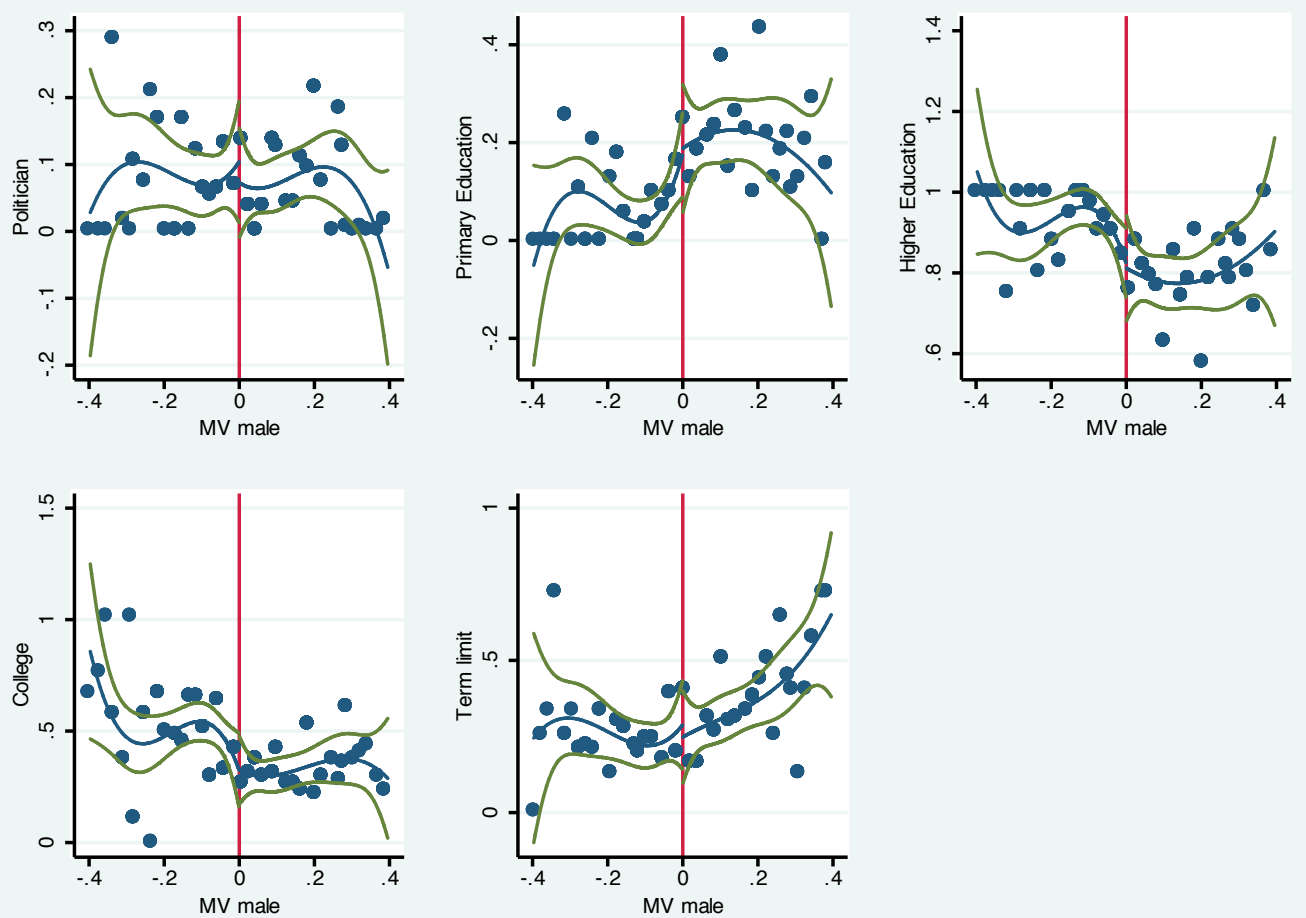

Notes. The blue line is a split third-order polynomial in margin of victory of the male candidate, fitted separately on each side of the margin of victory at zero (margin of victory is defined as greater than zero if the candidate that won is a male, lower than zero if the candidate that won is a female). The green lines are the 95 percent confidence interval of the polynomial. Scatter points are averaged over 2 percent intervals. Terms 2001-2005 and 2005-2008. Politician is equal to 1 if the mayor has previous experience in politics. Primary Education is equal to 1 if the mayor has at most an elementary school degree. Higher Education is equal to 1 if the mayor has at least high school degree. College is equal to 1 if the mayor has at least college degree. Term limit is equal to 1 if the mayor is not eligible for re-election because in a second consecutive term. 
Figure 4: Balance Tests - Mayoral Characteristics
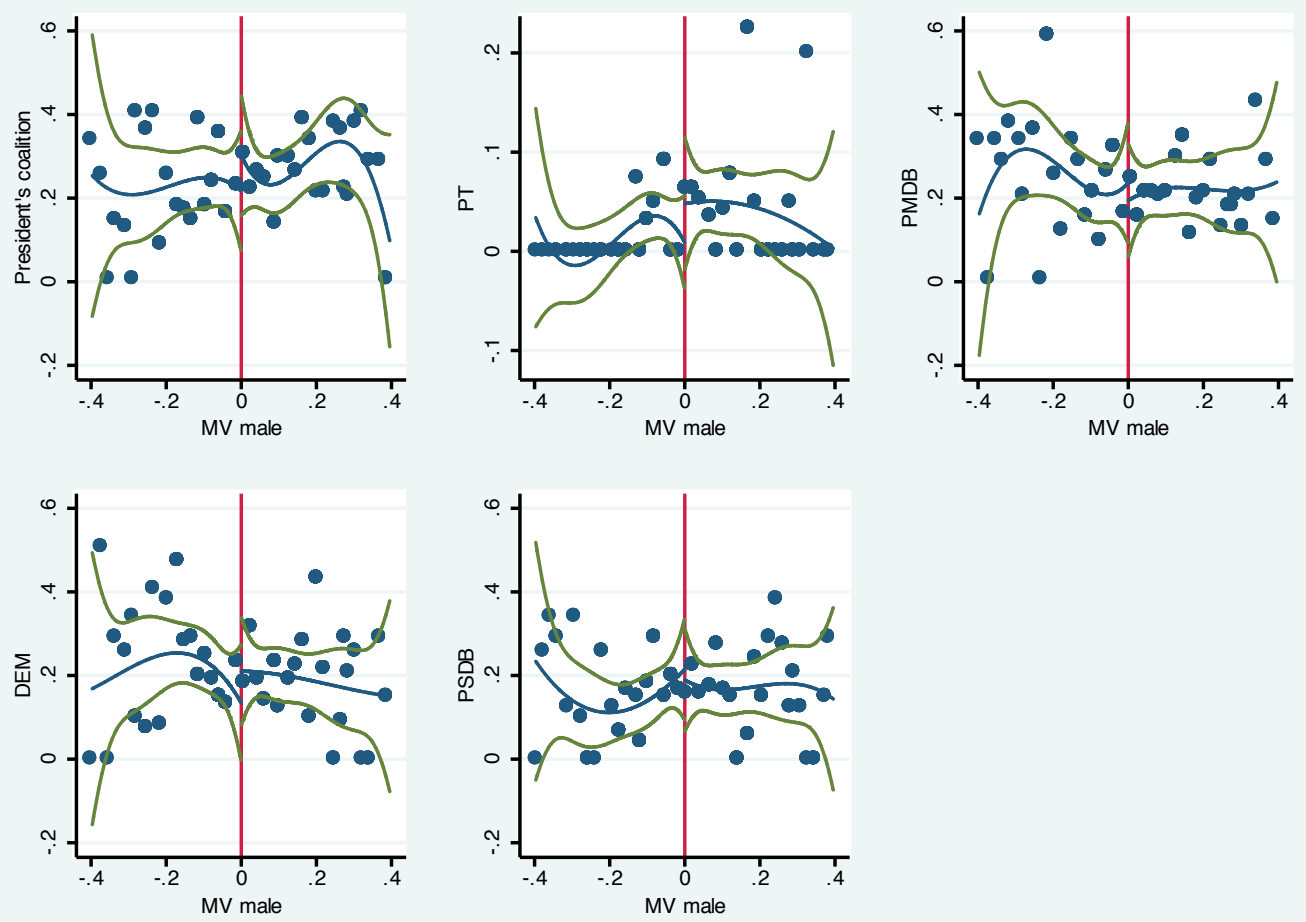

Notes. The blue line is a split third-order polynomial in margin of victory of the male candidate, fitted separately on each side of the margin of victory at zero (margin of victory is defined as greater than zero if the candidate that won is a male, lower than zero if the candidate that won is a female). The green lines are the 95 percent confidence interval of the polynomial. Scatter points are averaged over 2 percent intervals. Terms 2001-2005 and 2005-2008. President's coalition is the fraction of municipalities the mayor is affiliated to one of the president's coalition party. PSDB, DEM, $P M D B, P T$ is the fraction of municipalities where the mayor is affiliated with PSDB, DEM, PMDB, and PT, respectively. 
Figure 5: The Effects of Gender on Infrastructure Transfers, Health Outcomes and on Corruption
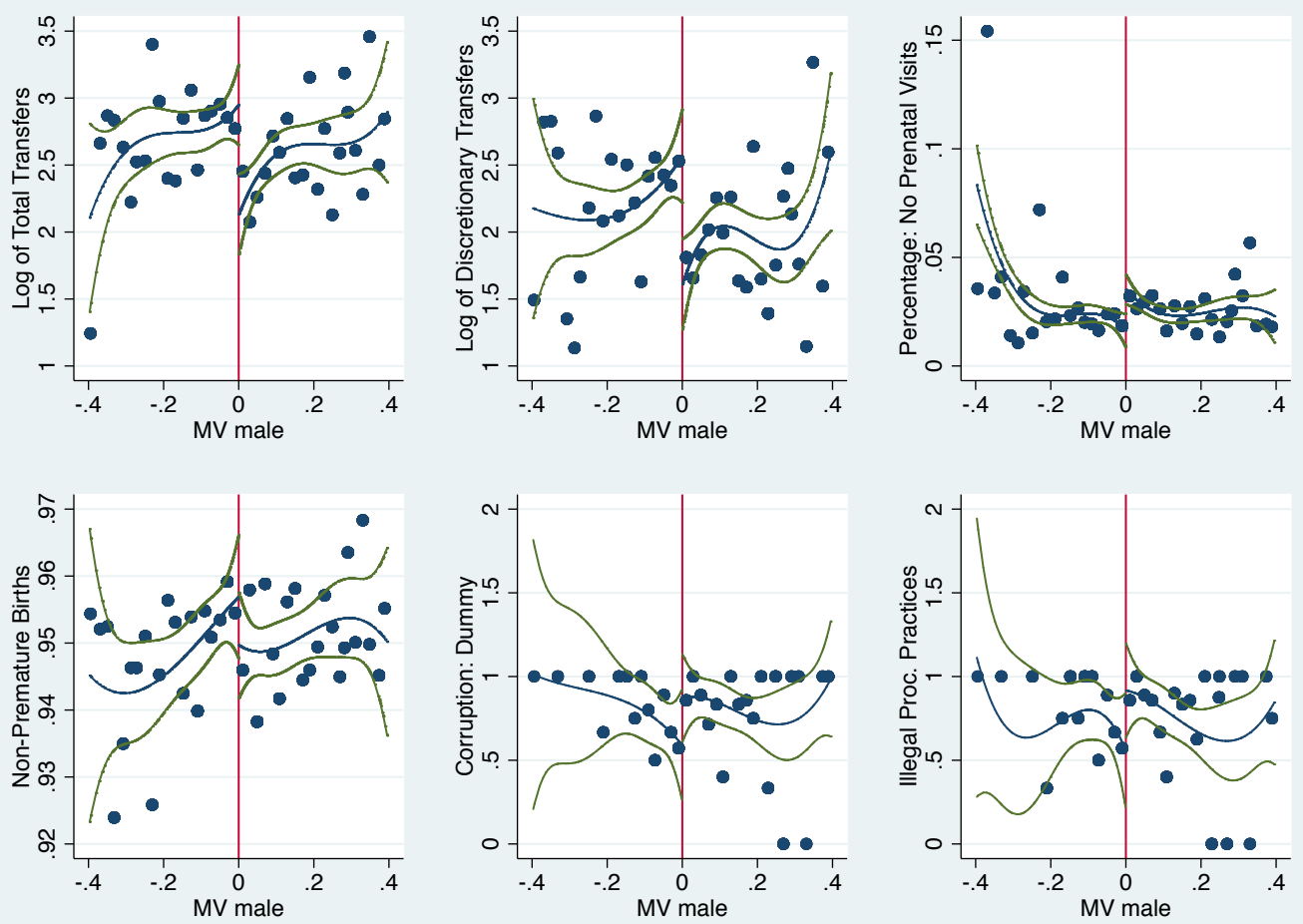

Notes. The blue line is a split third-order polynomial in margin of victory of the male candidate, fitted separately on each side of the margin of victory at zero (margin of victory is defined as greater than zero if the candidate that won is a male, lower than zero if the candidate that won is a female). The green lines are the 95 percent confidence interval of the polynomial. Scatter points are averaged over 2 percent intervals. Terms 2001-2005 and 2005-2008. Total transfers and Discretionary infrastructure transfers are yearly transfers from the federal government to municipalities (log of per-capita real values in 2000 Brazilian reais). No pre-natal visits is the yearly fraction of pregnant women without any pre-natal visit before the delivery at the municipality level. Non pre-mature births is the yearly fraction of births that are not premature at the municipality level. Charges of overall corruption, Charges of illegal procurement practices, is the fraction of audited municipalities with at least one episode of each one of these practices, respectively. 
Figure 6: The Effects of Gender on Electoral Outcomes and on the Number of Permanent and Temporary Public Employees

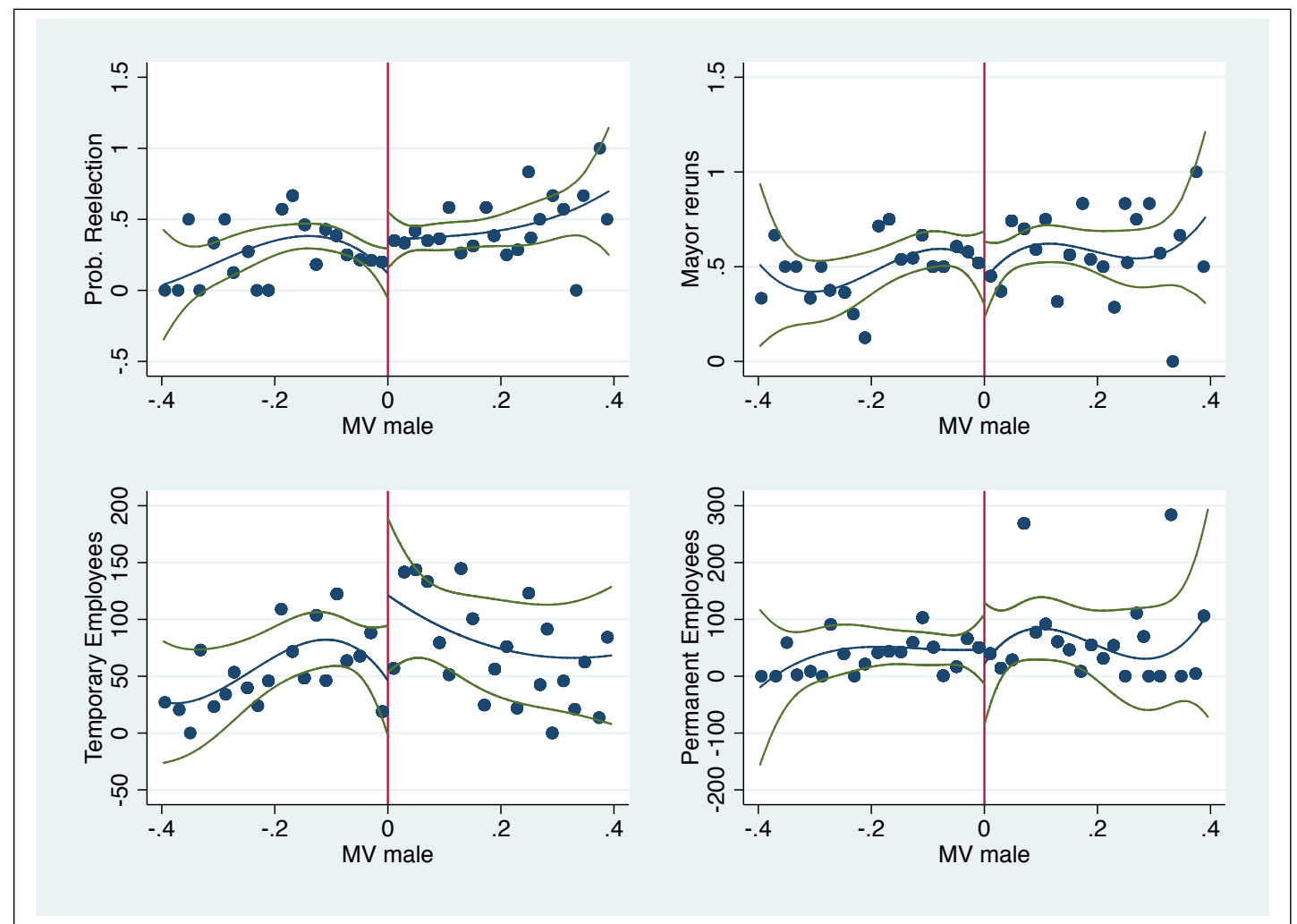

Notes. The blue line is a split third-order polynomial in margin of victory of the male candidate, fitted separately on each side of the margin of victory at zero (margin of victory is defined as greater than zero if the candidate that won is a male, lower than zero if the candidate that won is a female). The green lines are the 95 percent confidence interval of the polynomial. Scatter points are averaged over 2 percent intervals. Terms 2001-2005 and 2005-2008. Prob. re-election is equal to 1 if the incumbent mayor is reelected. Mayor re-runs is equal to 1 if the incumbent mayor re-run the subsequent election. The last two variables are defined for mayors who are eligible to run for re-election. Temporary public employee and Permanent public employee denote the number of public employees that have temporary and permanent employment contract in the municipal administration. 
Figure 7: Frequency of margin of victory, mixed-gender races

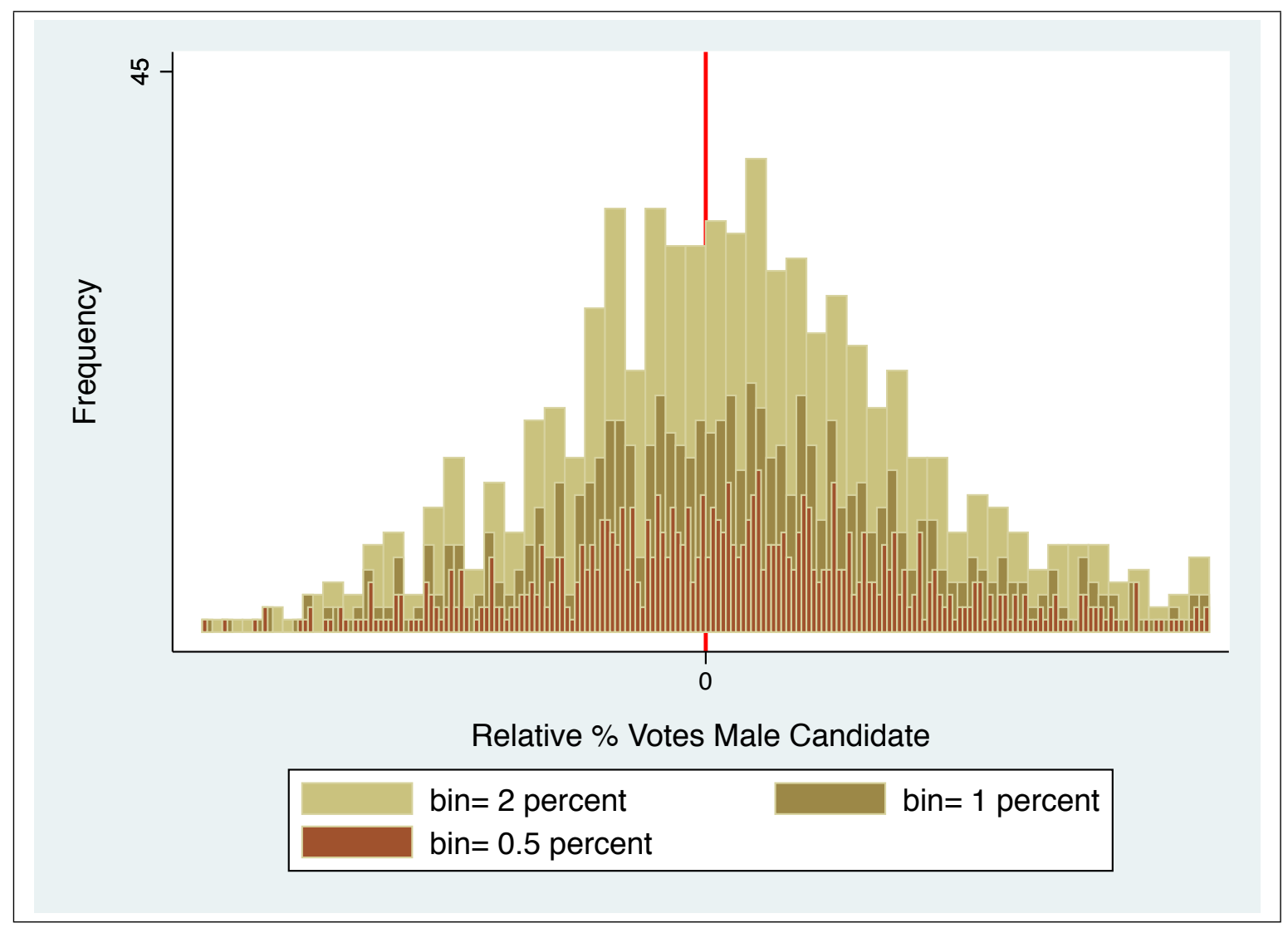

Notes. Frequency of two-candidate mixed gender races for term 2001 and 2005. 
Figure 8: McCrary Test

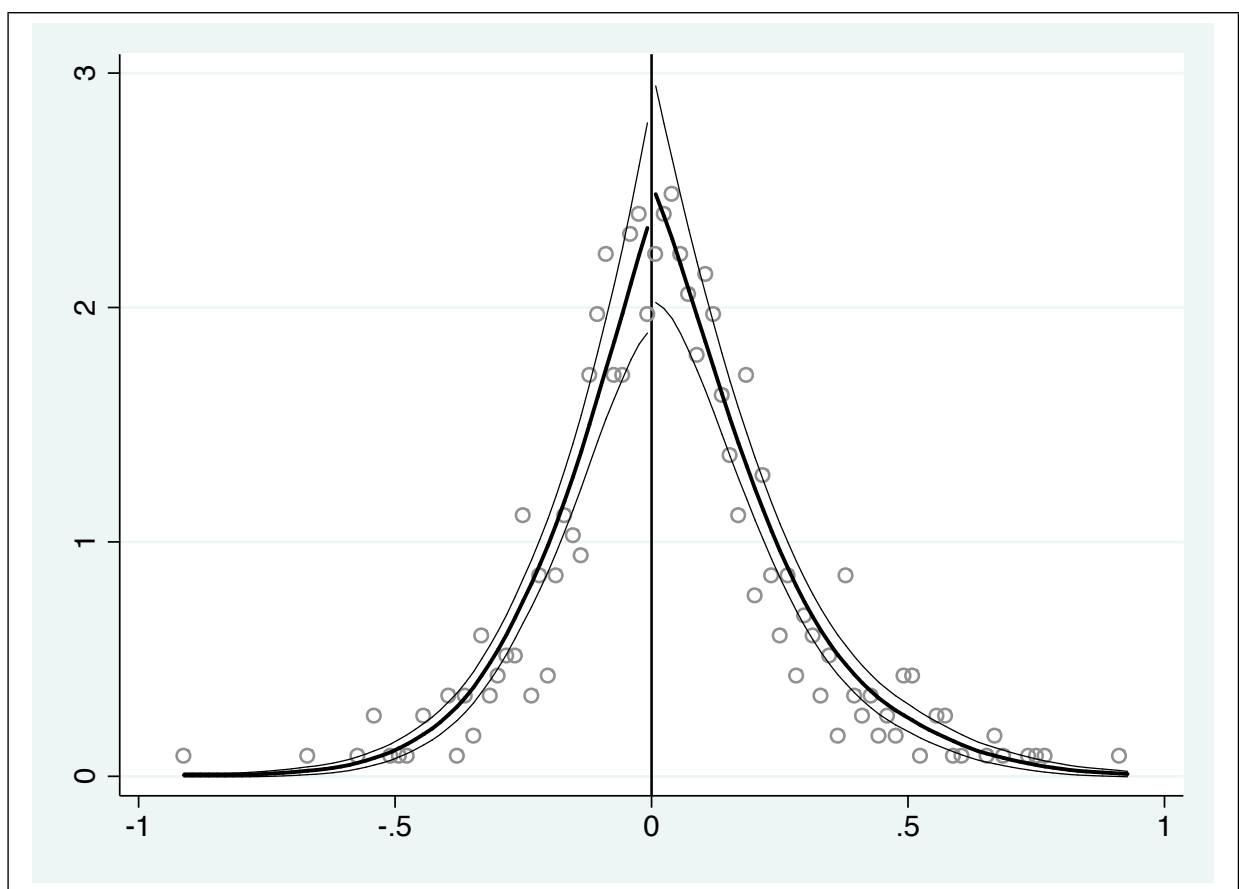

Notes. Weighted kernel estimation of the log density of two-candidate mixed gender races for term 2001 and 2005, performed separately on either side of the 0 Margin of Victory threshold. Optimal binwidth and binsize as in McCrary (2008). 


\section{Tables}


Table 1: Mayor and City Characteristics by Gender: Mixed Races vs Other Races

\begin{tabular}{lccccc}
\hline & $\begin{array}{c}(1) \\
\text { other } \\
\text { races }\end{array}$ & $\begin{array}{c}(2) \\
\text { obs }\end{array}$ & $\begin{array}{c}(3) \\
\text { mixed } \\
\text { races }\end{array}$ & $\begin{array}{c}(4) \\
\text { obs }\end{array}$ & $\begin{array}{c}(5) \\
\text { p-value }\end{array}$ \\
\hline Mayoral characteristics & & & & & \\
\hline Term limit & 0.288 & 10,022 & 0.319 & 723 & 0.083 \\
Politician & 0.064 & 10,034 & 0.081 & 723 & 0.077 \\
College & 0.398 & 10,034 & 0.395 & 723 & 0.869 \\
High School & 0.855 & 10,034 & 0.847 & 723 & 0.558 \\
Primary education & 0.145 & 10,034 & 0.153 & 723 & 0.558 \\
President's coalition & 0.271 & 10,034 & 0.248 & 723 & 0.167 \\
PSDB & 0.169 & 10,034 & 0.160 & 723 & 0.565 \\
DEM (PFL) & 0.160 & 10,034 & 0.212 & 723 & 0.000 \\
PMDB & 0.208 & 10,034 & 0.225 & 723 & 0.259 \\
PT & 0.054 & 10,034 & 0.030 & 723 & 0.006 \\
\hline Municipal characteristics & & & & & \\
\hline Population & 24,781 & 10,034 & 12,317 & 723 & 0.000 \\
Income per-capita (R $\$)$ & 163 & 10,034 & 131 & 723 & 0.000 \\
Literacy rate & 0.558 & 10,034 & 0.502 & 723 & 0.000 \\
Urban & 0.589 & 10,034 & 0.553 & 723 & 0.000 \\
Water supply & 0.581 & 10,034 & 0.549 & 723 & 0.000 \\
Electricity & 0.870 & 10,034 & 0.839 & 723 & 0.000 \\
Sewer & 0.229 & 10,034 & 0.170 & 723 & 0.000 \\
Absenteeism & 0.185 & 10,034 & 0.176 & 723 & 0.016 \\
Presence of local radio station & 0.210 & 10,034 & 0.109 & 723 & 0.000 \\
Gender wage gap & 0.134 & 10,034 & 0.101 & 723 & 0.000 \\
North & 0.082 & 10,034 & 0.084 & 723 & 0.832 \\
Northeast & 0.313 & 10,034 & 0.487 & 723 & 0.000 \\
Center & 0.082 & 10,034 & 0.093 & 723 & 0.316 \\
South & 0.216 & 10,034 & 0.130 & 723 & 0.000 \\
Southeast & 0.306 & 10,034 & 0.206 & 723 & 0.000 \\
\hline \hline
\end{tabular}

Notes. Two-candidate mixed races sample where one candidate is male and the other is female. Other races is the sample of all other elections that is not considered in the sample Two-candidate mixed races. Columns (1) and (3) report the average values in the respective samples; obs is the number of observations; $p$-value refers to the statistical significance of the difference between means. Politician is equal to 1 if the mayor has previous experience in politics. College is equal to 1 if the mayor has at least college degree. High School is equal to 1 if the mayor has at least high school degree. Primary Education is equal to 1 if the mayor has at most an elementary school degree. President's coalition is the fraction of municipalities the mayor is affiliated to one of the president's coalition party. $P S D B, D E M, P M D B, P T$ is the fraction of municipalities where the mayor is affiliated with PSDB, DEM, PMDB, and PT, respectively. Population is the number of resident inhabitants in 2000. Income refers to monthly per-capita income in 2000 and is measured in Brazilian reais. The following variables refer to the 2000 Census and are expressed in percentage terms: Urban population, Water access, Sewer, Electricity is the fraction of people living in urban areas, with water access, linked to sewerage system, and with electricity, respectively; Absenteeism is the fraction of voters that failure to appear in the election day; Literacy rate is the fraction of people above 20 who are literate; Presence of local radio station is equal to 1 if there is at least one local radio station in the municipality; Gender wage gap is the estimated gender salary gap, see paper for details about the estimation of this variable. North, Northeast, Center, South, and Southeast are the Brazilian macro-regions. 
Table 2: Summary Statistics: Outcomes - Mixed Races vs Other Races

\begin{tabular}{|c|c|c|c|c|c|}
\hline & (1) & $(2)$ & $(3)$ & (4) & $(5)$ \\
\hline & $\begin{array}{c}\text { mixed } \\
\text { races }\end{array}$ & obs & $\begin{array}{l}\text { other } \\
\text { races }\end{array}$ & obs & p-value \\
\hline Re-election rate & 0.352 & 7,141 & 0.347 & 493 & 0.806 \\
\hline Re-run rate & 0.573 & 7,149 & 0.549 & 493 & 0.290 \\
\hline Permanent public employees & 126 & 5,815 & 57 & 420 & 0.002 \\
\hline Temporary public employ & 136 & 5,815 & 80 & 420 & 0.003 \\
\hline No pre-mature births & 0.946 & 40,157 & 0.950 & 2,894 & 0.000 \\
\hline No pre-natal visits & 0.025 & 40,157 & 0.026 & 2,894 & 0.279 \\
\hline Total infrastructure transfer & 2.646 & 33,485 & 2.773 & 2,425 & 0.652 \\
\hline Non discretionary in & 0.659 & 33,485 & 0.646 & 2,425 & 0.000 \\
\hline Discre & 1.971 & 33,485 & 2.126 & 2,425 & 0.000 \\
\hline Charges of overall corruption & 0.821 & 156 & 0.765 & 1,958 & 0.111 \\
\hline Charges of illegal procurement practices & 0.776 & 156 & 0.666 & 1,958 & 0.005 \\
\hline \multicolumn{6}{|c|}{$\begin{array}{l}\text { Notes. two-candidate mixed races sample where one candidate is male and the other is female vs the sample all other } \\
\text { races. Columns }(1) \text { and ( } 3 \text { ) report the average values in the respective samples; obs is the number of observations; } \\
\text { p-value refers to the statistical significance of the difference between means. Non discretionary infrastructure transfers } \\
\text { and Discretionary infrastructure transfers are yearly transfers from the federal government to municipalities (log of } \\
\text { per-capita real values in } 2000 \text { Brazilian reais). Re-election rate is equal to } 1 \text { if the incumbent mayor is reelected. } \\
\text { Re-run rate is equal to } 1 \text { if the incumbent mayor re-run the subsequent election. The last two variables are defined } \\
\text { for mayors who are eligible to run for reelection. Non pre-mature births is the yearly fraction of births that are not } \\
\text { pre-mature at the municipality level; Non pre-natal visits is the yearly fraction of pregnant women without any pre- } \\
\text { natal visit before the delivery at the municipality level; Temporary public employee and Permanent public employee } \\
\text { denote the number of public employees that have temporary and permanent employment contract in the municipal } \\
\text { administration. Charges of overall corruption, Charges of illegal procurement practices, is the fraction of audited } \\
\text { municipalities with at least one episode of each one of these practices, respectively. Temporary public is the number } \\
\text { of temporary public employee in the last year of mayoral mandate. }\end{array}$} \\
\hline
\end{tabular}




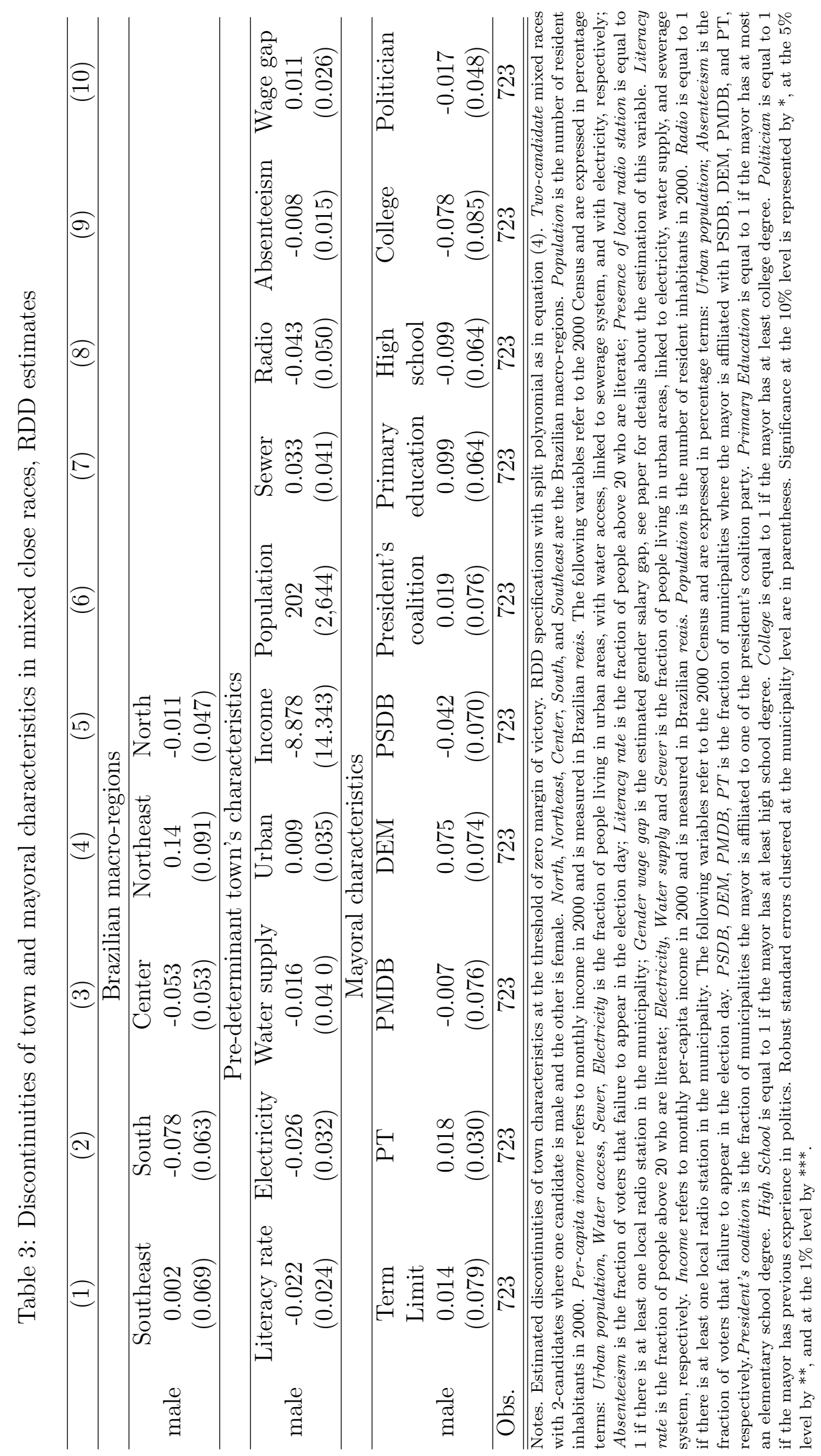


Table 5: The impact of gender on electoral outcomes, RDD estimates

\begin{tabular}{lcc}
\hline & $\begin{array}{c}\text { Probability of } \\
\text { re-election }\end{array}$ & $\begin{array}{c}\text { Probability of } \\
\text { Re-run }\end{array}$ \\
\hline OLS & $0.092^{* *}$ & 0.037 \\
Observations & $(0.043)$ & $(0.045)$ \\
\hline Spline polynomial & 493 & 493 \\
Observations & $0.220^{* *}$ & -0.038 \\
\hline Local linear regression & $(0.103)$ & $(0.115)$ \\
Optimal $h$ & 493 & 493 \\
Observations & $0.200^{* *}$ & -0.015 \\
Local linear regression & $(0.091)$ & $(0.116)$ \\
Half optimal $h$ & 18 & 13 \\
Observations & 350 & 290 \\
\hline
\end{tabular}

Notes. Dependent variables: Re-election rate is equal to 1 if the incumbent mayor is reelected, zero otherwise. Re-run rate is equal to 1 if the incumbent mayor re-run the subsequent election. Both excludes municipalities where the mayor is non-eligible to run for re-elections. Mixed races sample with two candidates where one is male and the other a female. $h$ denotes the interval of our running variable. For instance $h=13$ represents mixed gender races where margin of victory is between $-13 \%$ and $13 \%$. Robust standard errors clustered at the municipality level are in parentheses. Significance at the $10 \%$ level is represented by $*$, at the $5 \%$ level by $* *$, and at the $1 \%$ level by $* * *$. 
Table 6: The impact of gender (male mayors) on public employees, RDD estimates

\begin{tabular}{lcc}
\hline \hline & $(1)$ & $(2)$ \\
& Temporary Public & Permanent Public \\
\hline OLS & 24.352 & 26.436 \\
Observations & $(16.429)$ & $(21.023)$ \\
\hline Spline polynomial & 420 & 420 \\
& $75.441^{* *}$ & 22.825 \\
Observations & $(35.415)$ & $(39.572)$ \\
Local linear regression & 420 & 420 \\
& $64.761^{*}$ & -13.002 \\
Optimal $h$ & $(38.268)$ & $(34.980)$ \\
Observations & 9 & 12 \\
\hline Local linear regression & 163 & 215 \\
Half optimal $h$ & -3.176 & -38.434 \\
Observations & $(37.118)$ & $(40.363)$ \\
\hline
\end{tabular}

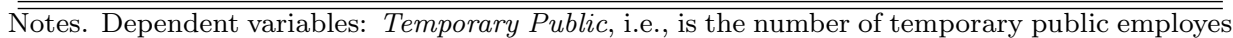
in the last year of the mayoral mandate; Permanent Public, i.e., is the number of permanent public employes in the last year of the mayoral mandate. RDD specifications with split polynomial and local linear regression as in equation (4) and (5), respectively. $h$ denotes the interval of our running variable. For instance $h=12$ represents mixed gender races where margin of victory is between $-12 \%$ and $12 \%$. Robust standard errors clustered at the municipality level are in parentheses. Significance at the $10 \%$ level is represented by $*$, at the $5 \%$ level by ${ }^{* *}$, and at the $1 \%$ level by $* * *$. 
Table 7: The impact of gender on health outcomes by education category, RDD estimates

\begin{tabular}{lcccc}
\hline & $(1)$ & $(2)$ & $(3)$ & $(4)$ \\
\hline & Illiterate & $\begin{array}{c}\text { Semi- } \\
\text { illiterate }\end{array}$ & $\begin{array}{c}\text { Primary } \\
\text { education }\end{array}$ & $\begin{array}{c}\text { Secondary } \\
\text { education }\end{array}$ \\
\hline Pale & $0.032^{*}$ & $0.025^{* *}$ & 0.004 & -0.002 \\
& $(0.016)$ & $(0.010)$ & $(0.004)$ & $(0.003)$ \\
\hline \multicolumn{5}{c}{ Panel B: No pre-mature births } \\
\hline Male & $0.032^{*}$ & $0.025^{* *}$ & 0.004 & -0.002 \\
Observations & $(0.016)$ & $(0.010)$ & $(0.004)$ & $(0.003)$ \\
\hline \hline
\end{tabular}

Notes. Panel A reports the results for our baseline estimates (as in equation (4). Panel A report the results when no pre-natal visits is the dependent variable. Panel B report the results when no pre-mature birth is the dependent variable. No pre-natal visits is the yearly fraction of pregnant women without any pre-natal visit before the delivery at the municipality level. No pre-mature births is the yearly fraction of births that are not pre-mature at the municipality level. In column 1, Illiterate is the fraction of illiterate women with No pre-mature births or Non pre-natal visits; in column2, semi-Illiterate is the fraction of semi-illiterate women with No pre-mature births or No pre-natal visits; In column 3, Primary education is the fraction of women with at most primary education and with No pre-mature births or with No pre-natal visits; in column 4, Secondary education is the fraction of women with at most secondary education and with No pre-mature births or No pre-natal visits, respectively. RDD specifications with split polynomial as in equation (4). Robust standard errors clustered at the municipality level are in parentheses. Significance at the $10 \%$ level is represented by *, at the $5 \%$ level by ${ }^{* *}$, and at the $1 \%$ level by $* * *$. 
Table 8: The impact of gender on temporary public employees, pre-natal visits and discretionary infrastructure transfers, heterogeneity results

\begin{tabular}{lccc}
\hline \hline & $\begin{array}{c}\text { Temporary } \\
\text { Public }\end{array}$ & $\begin{array}{c}\text { No pre-Natal } \\
\text { Visits }\end{array}$ & $\begin{array}{c}\text { Discretionary } \\
\text { Infrastructure } \\
\text { Transfers }\end{array}$ \\
\hline First-term & $122.026^{* * *}$ & 0.006 & $-0.703^{* * *}$ \\
Second-term & $(37.236)$ & $(0.005)$ & $(0.236)$ \\
Difference & -78.935 & $0.0019^{* * *}$ & $-0.766^{* *}$ \\
& $(161.915)$ & $(0.006)$ & $(0.353)$ \\
Observations & $-200.961^{* *}$ & 0.013 & -0.063 \\
\hline \hline
\end{tabular}

Notes. Dependent variables: Temporary Public denotes the number of temporary public employees in the last year of mayoral mandate. Pre-natal visits is the fraction of women with at least one pre-natal visit in the municipality. Treatment is a dummy that is equal to one when the mayor is male and zero otherwise. Treatment is interacted with a dummy variable that denotes whether the mayor is on her second-term, where the mayor face a binding term limit. RD specifications with 3rd-order spline polynomial in different subsamples. Mixed races sample with two candidates where one is male and the other a female. Robust standard errors clustered at the municipality level are in parentheses. Significance at the $10 \%$ level is represented by $*$, at the $5 \%$ level by ${ }^{* *}$, and at the $1 \%$ level by $* * *$. 